Article

\title{
Evaluation of Performance and Technological Characteristics of Battery Electric Logistics Vehicles: China as a Case Study
}

\author{
Xiaohong Jiang ${ }^{1}\left(\mathbb{D}\right.$ and Xiucheng Guo ${ }^{2, *}$ \\ 1 College of Automobile and Traffic Engineering, Nanjing Forestry University, Longpan Road 159\#, \\ Nanjing 210037, China; xiaohongjiang2009@163.com \\ 2 School of Transportation, Southeast University, Si Pai Lou 2\#, Nanjing 210096, China \\ * Correspondence: 101002320@seu.edu.cn; Tel.: +86-1390-516-6411
}

Received: 19 February 2020; Accepted: 5 May 2020; Published: 13 May 2020

check for updates

\begin{abstract}
The powertrain characteristics of battery electric logistics vehicles (BELVs) are extremely suited for the urban driving context and have a higher environmental protection potential for sustainable development, which can provide solutions for urban logistics decarbonization. The BELV is an important part of the Chinese national new-energy vehicle program, and the market penetration of BELVs has greatly improved. However, BELVs still have many technical shortcomings, which seriously affect their widespread acceptance. Therefore, it is necessary to reveal the technological characteristics and development direction of BELVs based on a large amount of marketing and technological data. This research reviewed the Chinese incentive policies and industrialization progress of BELVs. An evaluation system comprising 8 technological indicators for evaluating BELV technological progress was proposed. The distribution characteristics of the curb mass, vehicle volume, all-electric range, top speed, driving power, energy efficiency, traction battery and motor technology were analyzed for 2017 and 2019 markets' models. The vehicle total cost, vehicle performance and reliability of BELVs are not advantageous yet. However, all the performance parameters are improving year by year, constantly meeting logistics demands. The subsidies are needed for longer for the market to mature. Finally, several suggestions for the technical development direction of BELVs were proposed. All these results can be used to improve the vehicle performance, reliability and market penetration of BELVs.
\end{abstract}

Keywords: battery electric logistics vehicles; vehicle performance; technological characteristics; evaluation; all-electric range; energy efficiency; traction battery; subsidy

\section{Introduction}

City logistics face the major challenge of the rapid growth of express delivery businesses and the additional air pollution caused by diesel technology applied for it. The volume of the Chinese express delivery market is notable. The business volume exceeds the total volume of developed economies in the United States, Japan and Europe, accounting for more than 50\% of the global market share of express packages [1]. The volume of express delivery business has ranked first in the world for five consecutive years, which is the power source and stabilizer for the development of the global express package market. The problem of air pollution caused by vehicle emissions is becoming increasingly prominent. In 2018, the number of diesel trucks in China was 18.18 million, accounting for only $7.9 \%$ of the total number of vehicles, but the emission of nitrogen oxides (NOx) from these trucks accounted for $72.6 \%$ (3.789 million tons) of the total emissions. The emission of atmospheric particulate matter (PM) from these trucks accounted for more than $90 \%$ of the total PM emissions from 
all vehicles [2]. Therefore, solving the air pollution problem of freight vehicles is the top priority of Chinese environmental protection work.

The strategic transformation of the energy structure of China is imminent. China has long relied heavily on crude oil imports. In 2013, China surpassed the United States as the largest importer of gasoline and other liquid fuels. According to the China Energy Development Report of 2018, in 2017, Chinese crude oil imports totaled 420 million tons, and oil dependence on foreign countries increased by $2.4 \%$ to $67.4 \%$ year upon year, and even increased to $70.9 \%$ in 2018 [3]. There is an urgent need to reduce the Chinese energy dependence on foreign countries and realize the strategic transformation of its energy structure. Against the background of environmental and energy pressures and promotion of new technology development, many countries around the world, including China, have proposed exit schedules of fuel vehicles and provided relevant industrial policies to support the development of new energy vehicles (NEVs) [4]. NEVs include NE passenger cars (category M1 in Europe), NE buses and NE special purpose motor vehicles, among which special vehicles include logistics vehicles, postal vehicles and sanitation vehicles.

In 2018, the Chinese market accounted for $56 \%$ of the total sales of NEVs worldwide. The number and market penetration of NEVs in China is shown in Figure 1. By the end of 2019, the number of NEVs was 3.81 million. The growth rates from 2015 to 2019 were $430 \%, 133 \%, 90 \%, 63 \%$ and $46 \%$, respectively [3]. Although Chinese NEVs have experienced four years of rapid growth, in general, the proportion of NEVs in the whole Chinese car industry is $1.09 \%$, which is extremely low and has broad market prospects.

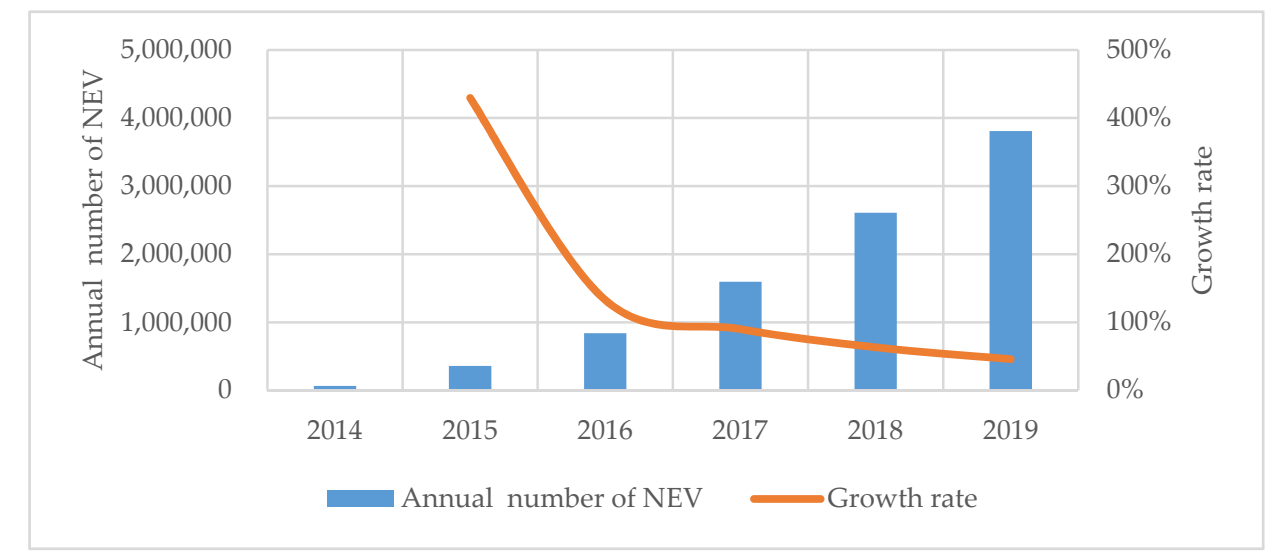

Figure 1. Industrial progress of new energy vehicles (NEVs) in China.

The number of new energy logistics vehicles (NELVs) in China is also increasing year by year. By the end of June 2019, the number of NELVs was 0.36 million. The penetration rate is $1.34 \%$, which is higher than the overall penetration rate of NEVs. Despite declining NEV subsidies and the sluggish growth of new energy buses (NEBs), NELVs have bucked the trend, and their output has risen sharply. The main driving factors include favorable policies, improvement of the NEV technology level, public awareness of environmental protection and market awareness.

Concerns about the environmental impacts of urban mobility have led to the development of alternative solutions, such as BELVs, which are highly applicable to certain sectors, namely urban logistics, since the powertrain characteristics of BELVs are extremely suited for the urban driving context [5]. BELV operation may contribute to decarbonization of urban logistics [6].

Despite these advantages, BELVs face notable challenges. The batteries have a lower energy density than internal combustion engine trucks (ICETs), which is why the range of these vehicles is limited. The recharging of batteries is time consuming, and the charging point infrastructure must be suitably in place before any market penetration, and the corresponding investment is important. The most difficult issue, however, is social acceptance of these vehicles, which is the last large hurdle 
for BELVs before penetrating the market to a large extent [7]. Their high capital cost is a barrier for consumers, and the range anxiety is perhaps the most important obstacle. Because the BELV range is smaller than that of ICETs and charging takes time, consumers worry that they will not be able to complete their journey [8]. An inadequate charging infrastructure exacerbates this problem [9-11]. However, as for most governments, Chinese roadmaps play an important role in promoting battery electric vehicles (BEVs) because of their high potential for technological improvement [12]. BELVs are an important part of the Chinese NEV program. At present, BELVs account for the majority of the Chinese NELV market, and BELVs account for $99 \%$ of the total NELVs [13]. In addition, new business models have been developed to compensate for some of their shortcomings, and policies have been implemented to support their development $[14,15]$.

However, the barriers for further development still exist. Previous research on NEVs have focused on life-cycle emissions, market penetration, energy efficiency, infrastructure, charging technology, etc. The main focus in the studies of the market penetration's influencing factors is on the perspective of customer behavior [16-19] and economic cost [20-26]. Lishan et al. conducted a consumer satisfaction survey about the people who have EVs in China, and found that the policy of "No traffic restrictions for EVs", charging infrastructure availability and technical support were the most important factors influencing the EVs users' preference [19]. Zhang et al. found that technical and policy improvements were more effective than improving the battery capacity at increasing the adoption potential of BEVs [16]. Yong et al. proposed a fuzzy-set qualitative comparative method to analyze the factors influencing the EV deployment, and stated that an effective policy mix needs to be promoted [17]. Hardman et al. stated that incentives were an effective policy measure in increasing plug-in electric vehicle (PEV) sales [18]. Other studies have reported that the cost competitiveness of BEVs is critical to their market success, so the impact of subsidies on BEV penetration was analyzed from an economic perspective. Based on simulations and literature reviews, these studies focused on the interaction between fiscal policy and customer acceptance and the resulting impact on market penetration [20-26]. In addition to policy, infrastructure development and charging technology were also identified as key factors in the rapid promotion of BEVs [9-11,27]. For example, Longjian et al. proposed a multi-agent-based pricing strategy for electric vehicle charging, considering customer satisfaction degree [27].

The above analysis of market penetration is EV-oriented and does not differentiate between electric cars, BELVs and battery electric buses (BEBs). BELV is considered as a possible alternative to the fuel-based logistics mode. Recent research focused on economic feasibility [28-31], benefit estimation [29,32-35], business mode [15], charging mode [9-11], policy support [36], competitive power [37], investment risk [38], dynamics [39] and barriers [40-42]. Juan et al. identified some research challenges related to the promotion of NELVs, including: (1) environmental-related issues, and (b) strategic, planning and operational issues [35]. More studies have analyzed the use of BELVs in urban delivery and assessed the social, environmental and economic impacts [29,34,43]. Teoh comparatively analyzed the fuel and energy used by BELVs during transportation under several scenarios with different charging strategies and charging technologies and calculated the life-cycle cost of the operation and the impact on $\mathrm{CO}_{2}$ emissions. His study found that the use of charging strategies significantly reduced life-cycle costs and did not have any strong negative impact on $\mathrm{CO}_{2}$ emissions [10]. To encourage the use of BELVs, Lebeau investigated users' choice intentions towards BELVs, using a joint-based choice analysis to understand the interaction between choice influencing factors and evaluate the trade-offs between BEV attributes in urban freight companies. Some effective policies to stimulate BEV adoption by users based on their preference structure were proposed [40]. Yong et al. explored Chinese logistics dispatchers' preference in electric tricycle-related policies [44].

Nonetheless, there have been few studies on BELV technology [8,45-49]. Mahmoudzadeh et al. analyzed the technological readiness of the different components of BEVs, including batteries, electric motors, power electronics, weight and aerodynamics characteristics, range extenders, super capacitors and charging options [8]. Sun summarized key technologies regarding batteries, charging technology, electric motors, control features and charging infrastructure of BEVs [45]. Research has focused on 
the technology of BEBs based on a large amount of technological data for all the models on the market [46-48]. Du et al. analyzed the distribution characteristics of the curb mass, top speed, driving power, all-electric range and energy consumption based on a large number of actual BEB models and their operational data [47]. Du et al. further focused on the comprehensive evaluation method of addressing the inner influencing principle of technological specification mentioned in a new subsidy scheme on the technological development direction of BEBs [48].

It could be seen that there has not been any research that has tracked the development of the BELVs based on the vehicle performance and technological data of all the market's models, which is the main objective of this research.

The Chinese BELV industry is characterized by multiple models (minivans, light trucks and light buses), different business models and various charging modes [13]. By the end of 2019, the BELV's market share had reached $99 \%$ of the NELV sales, indicating that there was a large amount of technological data available for analysis that could help to better understand BELV technology and its market development. However, a comprehensive study on the Chinese progress in BELV technology and industrialization has not yet been conducted. There are still many technical shortcomings in BELVs, which seriously affect the widespread acceptance of them. Therefore, it is necessary to reveal the status quo and development direction of the technical performance of BELVs based on extensive market and technical data and evaluate the impact of state financial subsidies on the development of BELVs.

To fill these knowledge gaps, this study aimed to comprehensively study the technical development of BELVs in China by using extensive marketing and technological data. After analyzing the market penetration's influencing factors of BELVs, a system to evaluate BELVs technological progress is proposed. The vehicle performance and battery motor technologies of BELVs are evaluated for BELV models. Finally, the key challenges and suggestions for the BELV industry development are identified.

This paper is structured as follows. Section 2 reviews the incentive policies for BELVs in China. Section 3 evaluates the overall state of BELV industrialization and analyses market penetration's influencing factors. Section 4 examines the progress of BELV technology based on the market's models. Section 5 analyzes the challenges and suggestions to BELV technologies and industrialization. Conclusions are provided in Section 6.

\section{Review of BELV Incentive Policies}

China has been promoting the application of NEVs in three phases since 2009. The first phase (2009-2012) of the promotion of NEV applications in China was focused on support and acquisition subsidies for NEB in 13 cities [50].

In the second phase (2013-2015), the area of application was expanded to 88 cities, and BELVs began to be promoted and applied [51]. The incentive policies of BELVs mainly focus on the national financial subsidies. In addition to the purchase subsidy, three subsidy policies were proposed: exemption from vehicle purchase tax from 2014 [52], exemption from travel tax from 2015 [53] and access to supportive electricity price from 2014 [53].

The third phase (from 2016 onwards) will extend the application to the whole country [54]. In September 2019, the Central and State Council of China issued an outline of building a powerful transportation industry, which requires that all urban logistics vehicles achieve electrification, new energy and cleanliness by 2035 [55].

The BELVs must meet certain technical standards to qualify for the purchase subsidy, exemption from the purchase tax and travel tax [50-53,56-58]. The technical standards are mainly based on three indicators: battery energy density, energy consumption and all-electric range (AER). The national subsidy standard and technical standards for BELVs from 2009 to 2022 are summarized in Table 1. 
Table 1. The national purchase subsidy standards and technical standards for battery electric logistics vehicles (BELVs) from 2009 to 2019.

\begin{tabular}{|c|c|c|c|c|}
\hline Year & Subsidy Standard & $\begin{array}{l}\text { Energy } \\
\text { Density, } \\
\text { Wh/kg }\end{array}$ & $\begin{array}{c}\text { Energy } \\
\text { Consumption, } \\
\text { Wh/(km.kg) }\end{array}$ & $\begin{array}{l}\text { All-Electric Range } \\
(\mathbf{k m})\end{array}$ \\
\hline 2009-2012 & $\begin{array}{l}\text { 60,000 RMB per new energy light } \\
\text { commercial vehicle }\end{array}$ & / & / & $\geq 50$ \\
\hline 2013-2016 & $\begin{array}{c}2000 \mathrm{RMB} / \mathrm{kWh}(2013), 1900 \mathrm{RMB} / \mathrm{kWh} \\
(2014), \\
1800 \mathrm{RMB} / \mathrm{kWh}(2015,2016)\end{array}$ & / & / & $\geq 80$ \\
\hline 2017 & $\begin{array}{c}1500 \mathrm{RMB} / \mathrm{kWh} \text { for the part below (and } \\
\text { including) } 30 \mathrm{kWh} \\
1200 \mathrm{RMB} / \mathrm{kWh} \text { for the part between } 30 \text { and } \\
50 \text { (including) } \mathrm{kWh} \\
1000 \mathrm{RMB} / \mathrm{kWh} \text { for the part above (and } \\
\text { including) } 50 \mathrm{kWh}\end{array}$ & $\geq 90$ & $\leq 0.5$ & $\geq 80$ \\
\hline 2018 & $\begin{array}{c}850 \mathrm{RMB} / \mathrm{kWh} \text { for the part below (and } \\
\text { including) } 30 \mathrm{kWh} \\
750 \mathrm{RMB} / \mathrm{kWh} \text { for the part between } 30 \text { and } \\
50 \text { (including) } \mathrm{kWh} \\
650 \mathrm{RMB} / \mathrm{kWh} \text { for the part above (and } \\
\text { including) } 50 \mathrm{kWh}\end{array}$ & $\geq 115$ & $\leq 0.4$ & $\geq 80$ \\
\hline 2019 & $350 \mathrm{RMB} / \mathrm{kWh}$ & $\geq 125$ & $\leq 0.3$ & $\geq 80$ \\
\hline 2020-2022 & $\begin{array}{c}315 \text { RMB/kWh (2020), } 252 \text { RMB/kWh (2021), } \\
176 \text { RMB/kWh (2022) }\end{array}$ & $\geq 125$ & $\leq 0.29$ & $\geq 80$ \\
\hline
\end{tabular}

As shown in Table 1, the technical standards of battery energy density and energy consumption have been increased year by year. In recent years, the requirement for AER is $80 \mathrm{~km}$ or more. The national subsidy amount was 60,000 RMB per new energy light commercial vehicle before 2012 . Since 2013, the state subsidies have been declining year by year. Subsidies for BELVs based on the battery's capacity were first proposed in 2013. From 2017 to 2018, the subsidy was issued as sectional excess and accumulation. On 23 April 2020, four ministries issued the notice on improving financial subsidy policies for the promotion and application of new energy vehicles, which specifies that the subsidy period will be extended to 2022, and determines that the subsidy rates for 2020-2022 will be reduced by $10 \%, 20 \%$ and $30 \%$ from the previous year, respectively [ 57 ].

\section{Analysis of Market Penetration's Influencing Factors for BELVs}

\subsection{Industrialization Progress}

Both the number and market penetration of NELVs in China are increasing year by year, which is evident in Figures 2 and 3, respectively. The growth rates from 2015 to 2018 were 643\%, 140\%, 155\% and $25.6 \%$, respectively [13]. Both NEVs and NELVs experienced a steep growth in 2015. The growth rate of NEVs has decreased year by year since 2016, but the growth rate of NELV vehicles has continued to increase since 2016. Based on the data released by the Traffic Administration of the Ministry of Public Security, the number of NELVs was 0.36 million by the end of June 2019 [3]. The penetration rate of NELVs is also increasing year by year. By the end of June 2019, the penetration rate was $1.34 \%$, which is higher than the overall penetration rate of NEVs. 


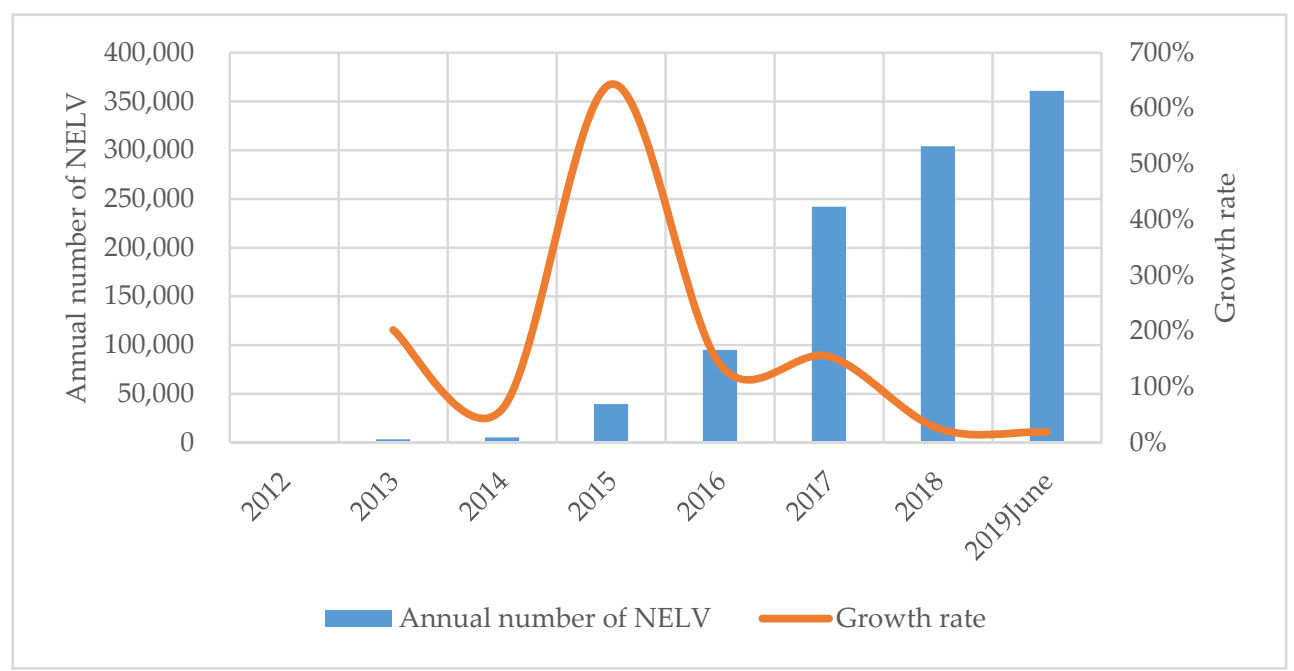

Figure 2. Industrial progress of new energy logistics vehicles (NELVs).

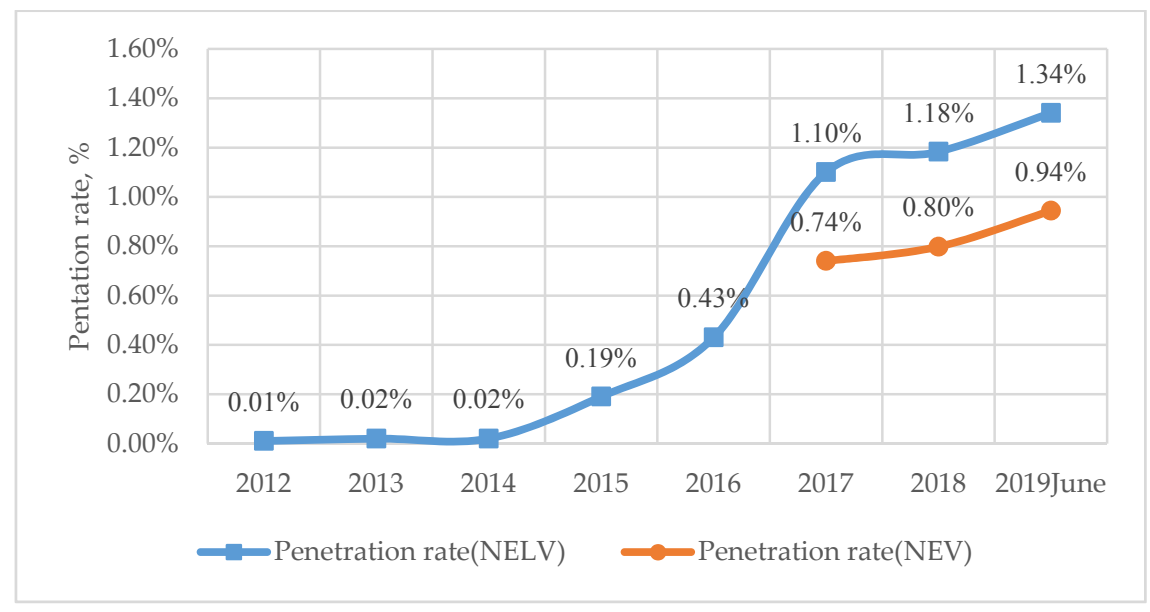

Figure 3. Penetration rates of NELVs and NEVs.

\subsection{Market Penetration's Influencing Factors}

Despite declining BELV subsidies, the NELV industry has bucked the trend, and its output has increased sharply. The main driving factors include favorable policies, improvement of the NEV technology level, public awareness of environmental protection and market awareness.

- Policy promotion

The incentive polices have promoted the growth of NELVs. From 2013, relevant policies on the promotion of NELVs were introduced for the first time [51], and NELVs began to be applied. From 2016 onwards, the promotion began to extend the application to the whole country. As seen from Table 1 and Figure 3, the growth of market penetration rates is closely related to the subsidies. In addition to the subsidy policies mentioned in Section 2, the guarantee for the right-of-way is also adopted to guide the transition from ICETs to NEVs. The pilot areas of NEV promotion put forward measures such as simplifying the licensing procedures, opening the right-of-way and preferential parking fees to guarantee the right-of-way. Since 2018, China has promoted the demonstration project of urban green delivery in 22 cities, which also strongly promoted the development of NELVs, and another 24 cities are involved in the second batch of demonstration projects announced at the end of 2019. 
- Improvement of the NEV technology level

Domestic pure electric vehicle technology is gradually approaching the international advanced level. For example, the driving range reliability, safety and power level have been continuously improved. With the continuous optimization of comprehensive benefits, the capacity of large-scale commercial promotion has gradually been established.

- Public awareness of environmental protection

With the increasing awareness of environmental protection, the public has increasingly realized the importance of environmental protection and actively participates in social supervision of environmental protection.

- Market awareness

Commercial vehicle fleets constitute a favorable entry for BEVs into the transport system [41]. In terms of market recognition, the right-of-way, cost and social responsibility promote companies to choose NELVs. Compared with ICETs, NELVs have clear advantages in terms of the right-of-way, data collection ability, notable oil and electricity price differences, easy management, etc., which provides value to NELV users in operation optimization. NELVs can obtain more rights-of-way because of their little impact on local air pollution, so they can reduce the costs for urban distribution companies. BELVs have their own complete data collection system and can collect real-time online data, which plays an important role in optimizing the operation efficiency of companies and reducing costs. China has defined the public data acquisition technical specifications for NEVs and charging infrastructure. This technical specification requires 61 real-time upload data, including 10 driving motor data, 3 vehicle position data, 3 engine data, 11 vehicle data, 12 fuel cell data, 12 extreme value data and 10 alarm data [59]. NEVs in the public service field are required to upload data in real time, and NEVs in the private sector report on demand [59]. Since 2018, Shenzhen, China, has carried out hierarchical management and given priority of the right-of-way to NELVs that have voluntarily installed radio frequency identification devices, accessed global position system data and accepted electronic filling [60]. The price difference between fuel oil and electricity is distinct. Oil prices are relatively stable, with little room for fluctuations. However, the difference in electricity prices between different regions and periods is very large, which leads to much space for cost optimization. BELVs can substantially reduce the workload of vehicle management departments, and power consumption management is easier than oil management. In summary, NELVs have become an important means for promoting the transformation and development of freight logistics. Domestic logistics companies have issued logistics electrification plans. Among them, Chinese Post, Jingdong, Shunfeng, Yuantong, Suning and other companies play a leading role in the application of NELVs. Chinese Post expects to achieve $100 \%$ of new NELVs in cities by the end of 2020. Jingdong logistics will replace all logistics vehicles in Tianjin and Hebei with BELVs, and Shunfeng planned to promote tens of thousands of NELVs, more than half of which will be operated in cities such as Beijing, Guangzhou and Shenzhen serving trunk, branch and terminal distribution. Cainiao proposed to realize city-wide distribution of NELVs in 100 cities by the end of 2020.

\subsection{Distribution of the NELV Market}

NELVs include battery electric logistics vehicles (BELVs), range-extended electric logistics vehicles (REELVs), plug-in hybrid electric logistics vehicles (PHELVs), fuel cell electric logistics vehicles (FCELVs) and energy storage trolleybuses (ESTBs). Among them, because of range limitations, the first four are suitable for urban logistics, while the last one is suitable for intercity logistics. In China, the number of BELVs accounts for the vast majority. In 2017, the total number of BELVs was 145,930, and the total number of the other vehicles was 840 [13]. The major reason is the price gap between the manufacture retail price (MRSP) and the post-subsidy price resulting from subsidy policies. Figure 4 
shows a price comparison of four light trucks in 2017. After subsidy, the price of BELVs is significantly lower than that of the other three kinds of vehicles. Therefore, all manufacturers basically choose to promote BELVs, and BELVs thus account for $99 \%$.

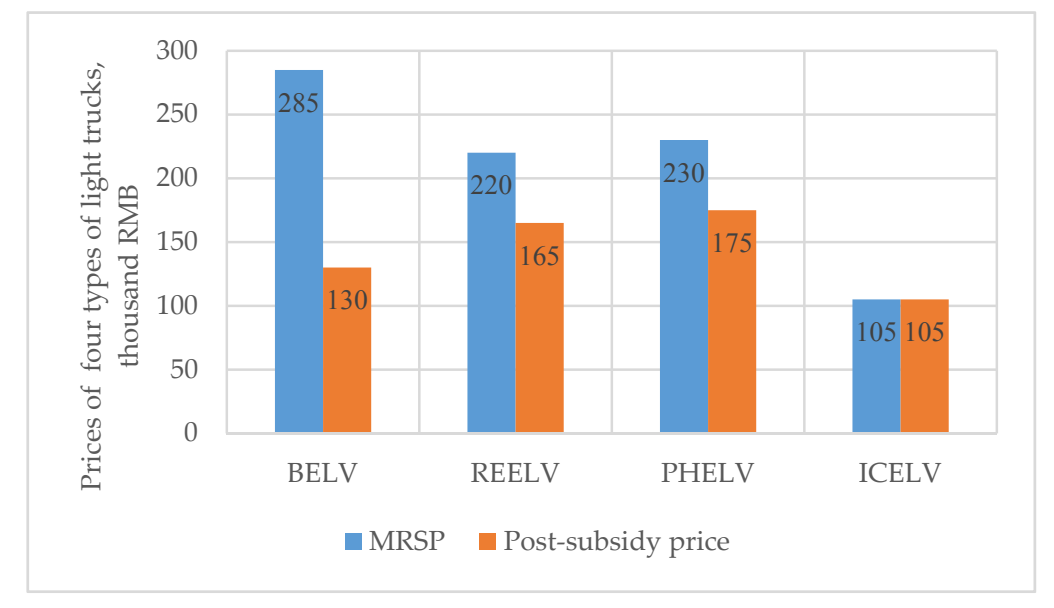

Figure 4. Price comparison of four light trucks in 2017.

According to the recommended catalogue of NEVs issued by the Ministry of Industry and Information Technology, NELVs include battery electric van-type transport vehicles, battery electric rail-type trucks, battery electric refrigerated vehicles, battery electric bin grid transport vehicles, battery electric traction vehicles and battery electric semi-trailer traction vehicles. The NELV model composition is very complex. Generally, for the convenience of statistics, trucks are usually divided into micro trucks, light trucks, medium trucks and heavy trucks, according to their weight. There are five types of NELVs according to weight in China: new energy minivans (NE minivans), new energy light buses (NE light buses), new energy minitrucks (NE minitrucks), new energy light trucks (NE light trucks) and new energy medium and heavy trucks (NE medium and heavy trucks). Figure 5 shows the market proportions of these five types of NELVs based on market penetration data. In 2017, NE minivans, light trucks and light buses accounted for $40 \%, 37.4 \%$ and $15.6 \%$ respectively, of the total market, at a combined share of $93 \%$.

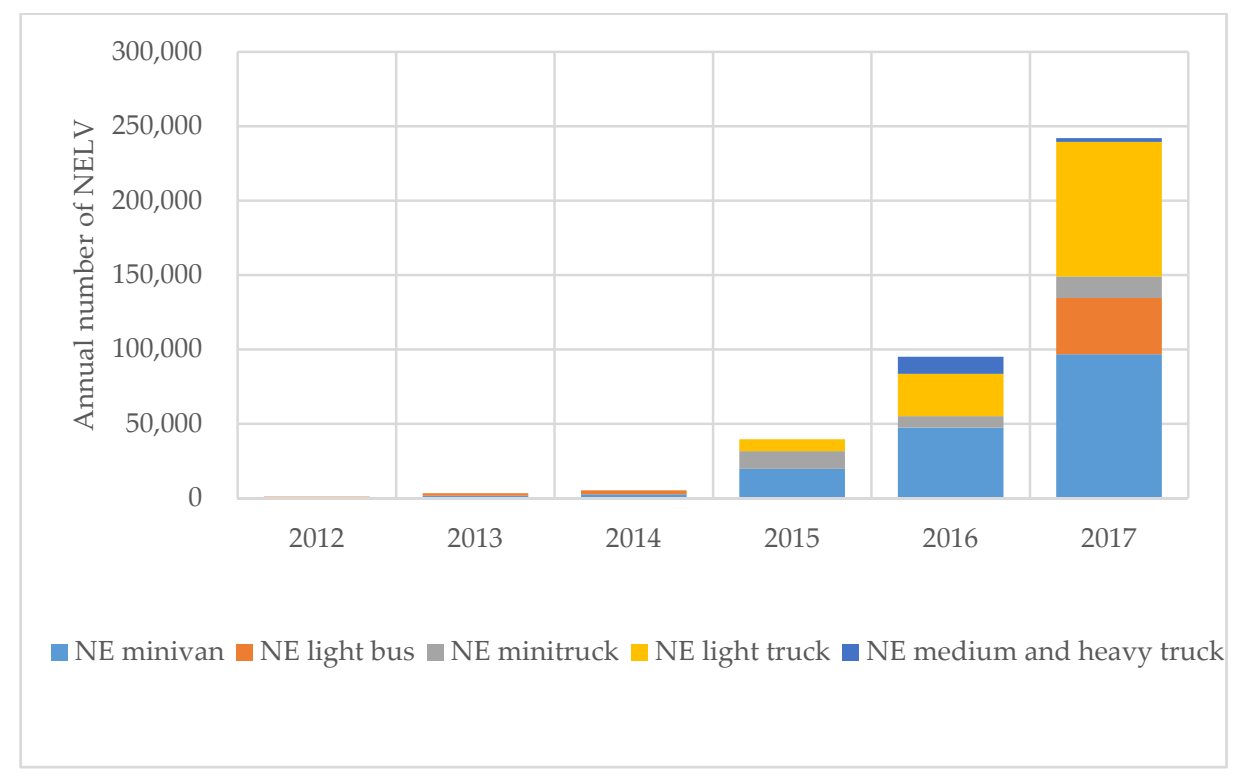

Figure 5. Annual numbers of the various types of NELVs. 
NELVs have been widely used in the field of urban distribution. Limited by the current technical level of NELVs, NELVs are mainly light closed trucks and light van trucks, with AERs ranging from 200 to $300 \mathrm{~km}$. Therefore, NELVs are mainly used in the field of urban distribution, especially in the last express delivery section. Upgrading the retail industry provides development opportunities for the development of NELVs. NELVs have gradually penetrated many industries, such as retail, medical, home furnishing, fresh produce and other industries.

\section{Evaluation of Performance and Technologies for BELVs}

\subsection{Evaluation Method}

BELVs are classified into detailed categories based on the above-mentioned definitions. The minivan, light bus and light truck account for more than $90 \%$ of the market share, and battery electric vehicles account for $99 \%$ of the market share. Therefore, the following technological characteristics focus on typical models of these three BELVs, including the battery electric minivan (BE minivan), battery electric light bus (BE light bus) and battery electric light truck (BE light truck).

This evaluation system consists of two components, namely, vehicle performance evaluation and battery motor technologies evaluation. Vehicle performance is the evaluation parameter for BELVs users, which includes 4 parameters: the curb mass (CM), vehicle volume, AER and top speed. Battery and motor technologies are the technical support provided by the manufacturer to achieve the above vehicle performance indexes, including driving power, energy efficiency, traction battery technology and traction motor technology. These 4 parameters are integrated with 4 battery and motor technologies to examine the technological progress associated with BELVs development.

The following evaluation analysis selected 2017 and 2019 data. The 2019 data is the most recent and reflects the latest vehicle performance and battery motor technology from BELVs in China. China's NELVs penetration rate started at over $1 \%$ in 2017 and has been growing steadily year by year [13]. The data for the 2017 BELVs market is therefore used to analyze vehicle performance and technology at the beginning of its life. The vehicle performance and technologies for 2017 and 2019 were analyzed separately and a comparative analysis was performed. While the 2017 and 2019 are only three years apart, the number of BELVs models has grown more [61]. This paper evaluated the performance of the vehicle by analyzing the vehicle performance parameters, battery motor technology and identified problems. We tried to explore the future development trend of battery motor technologies of BELV and make suggestions for improvement in accordance with the national technical requirements of BELVs.

The data of 2017 BELVs come from the 2018 development report of Chinese NELVs [13]. This report tracked the market's main selling models, including $3 \mathrm{BE}$ minivans, $5 \mathrm{BE}$ light trucks and $5 \mathrm{BE}$ light buses models. The data of 2019 BELVs are sourced from a webpage [61], which provides a library of BELVs for the Chinese market, including $11 \mathrm{BE}$ minivans, $20 \mathrm{BE}$ light trucks and $28 \mathrm{BE}$ light buses models.

\subsection{Vehicle Performance}

\subsubsection{Distribution Characteristics}

The CM of BELVs is largely influenced by the battery energy consumption rate. In 2017, the $\mathrm{CM}$ of BE minivans, BE light trucks and BE light buses was approximately $500-1000 \mathrm{~kg}, 1500 \mathrm{~kg}$ and $500-1300 \mathrm{~kg}$, respectively [13]. In 2019, the average CM of BE minivans, BE light trucks and BE light buses were approximately $935 \mathrm{~kg}, 1381 \mathrm{~kg}$ and $1308 \mathrm{~kg}$, respectively. The present CM distribution of various BELVs are shown in Figure 6, which could be seen that CM has grown in recent years. 


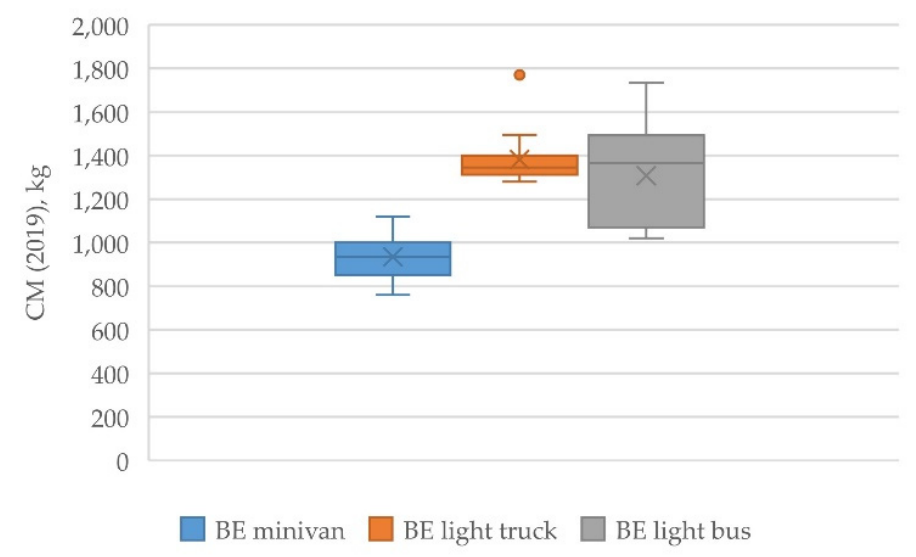

Figure 6. Curb mass (CM) distribution of the various BELVs (2019).

Weight restrictions common in urban areas limit the access of certain BELVs that would have been authorized if they had been diesel powered. According to regulation GA802-2014 promulgated by the Public Security Ministry, the total mass of blue brand light trucks must be below $4500 \mathrm{~kg}$, while the CM of internal combustion engine (ICE) light trucks is usually $3000 \mathrm{~kg}$. According to the subsidy policy for NEVs released by the state in 2018, the indicator of the energy consumption per unit of mass $\left(E_{\mathrm{kg}}\right)$ must reach $0.35 \mathrm{Wh} /(\mathrm{kg} \cdot \mathrm{km})$ to enjoy full subsidies. To meet the $E_{\mathrm{kg}}$ requirements, the actual dead mass of the NE light truck must be below $2910 \mathrm{~kg}$, so the CM of NE light trucks is $1500 \mathrm{~kg}$, only half of that of ICE light trucks. The inevitable reality is that BELVs are much heavier than ICE trucks and buses of an equivalent size. This occurs because of the large mass of the large-capacity batteries due to their limited energy density, as low as $0.35 \mathrm{Wh} /(\mathrm{kg} \cdot \mathrm{km})$.

\subsubsection{Vehicle Volume Distribution Characteristics}

The vehicle volume can reflect the CM. The volumes of various BELVs are shown in Figure 7. At present, the volumes of BE minivans, BE light trucks and BE light buses are approximately $5 \mathrm{~m}^{3}$, $17 \mathrm{~m}^{3}$ and $8.5 \mathrm{~m}^{3}$, respectively. Both BE minivans and BE light trucks have increased in volume but BE light buses have decreased in volume.

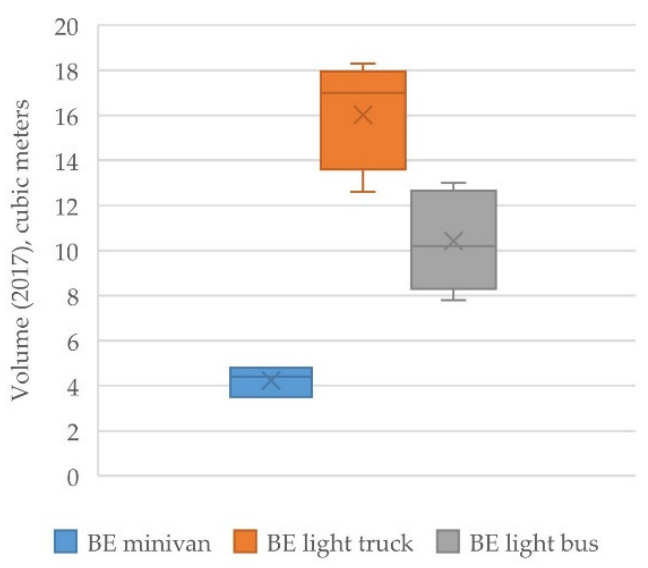

(a)

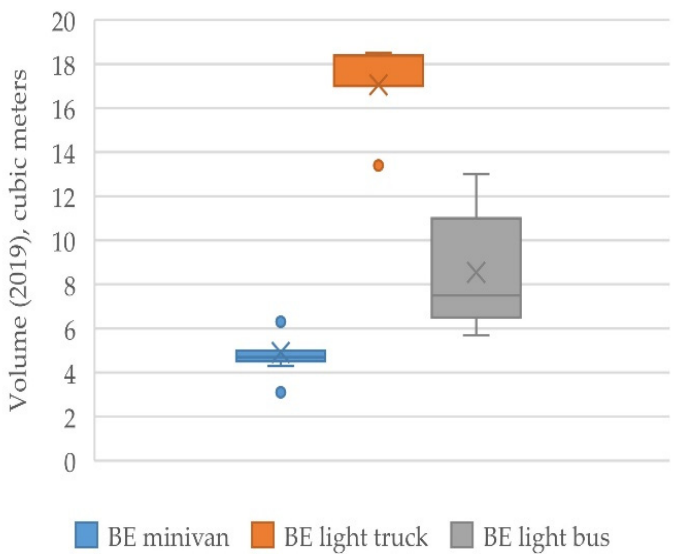

(b)

Figure 7. Volume distribution of the various BELVs, (a) 2017 and (b) 2019. 


\subsubsection{AER Distribution Characteristics}

According to survey data, $86 \%$ of urban logistics customers' average daily mileage is basically below $200 \mathrm{~km}$, but approximately $70 \%$ of customers indicated that due to business reasons, the driving mileage over approximately 1-2 days in a 10-day period can exceed $200 \mathrm{~km}$ [13]. The AER is a very important parameter for BELVs users [8,47].

The official AER for BELVs operating in China is shown in Figure 8. In 2019, the average AER for BE minivans, BE light trucks and BE light buses were approximately $255 \mathrm{~km}, 241 \mathrm{~km}$ and $233 \mathrm{~km}$, respectively. As seen from the data of 2017 and 2019, all BELVs have increased in AER in recent years. The AER of BELVs currently on the market are $80 \mathrm{~km}$ or more that meet the requirements of the national technical standards listed in Table 1.

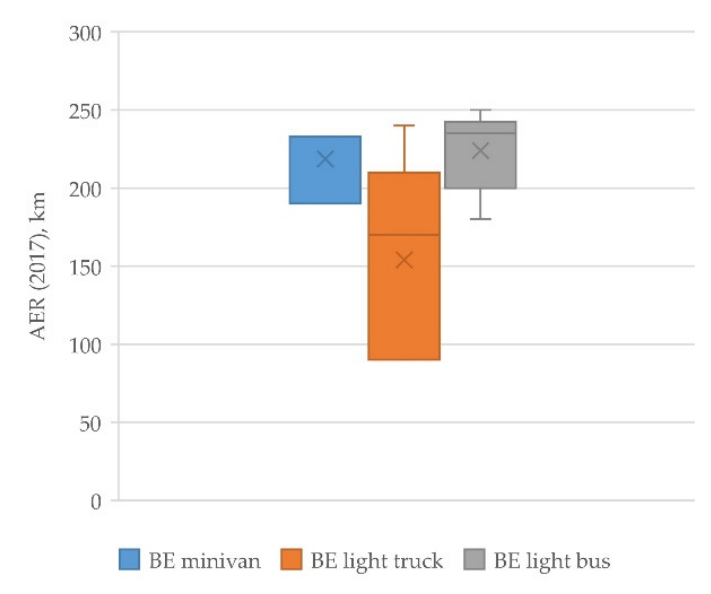

(a)

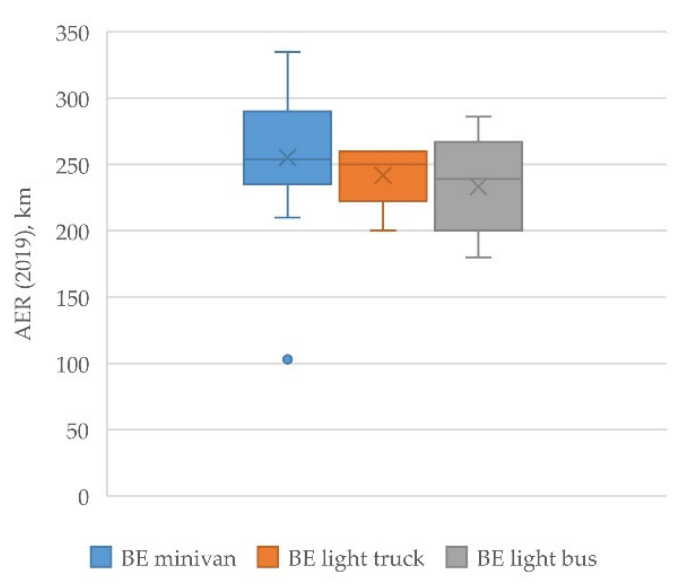

(b)

Figure 8. All-electric range (AER) distribution of the various BELVs, (a) 2017 and (b) 2019.

In addition, due to battery attenuation every year, the actual AER decreases rapidly year by year, which makes it difficult to truly meet the logistics demand [13]. AER anxiety is particularly prominent in intercity logistics. Most of intercity logistics transportation relies on heavy trucks driving on highways, and the daily miles travelled often exceeds $600 \mathrm{~km}$. However, there are currently no BE heavy trucks on the Chinese market with AER of $600 \mathrm{~km}$ or more.

\subsubsection{Top Speed Distribution Characteristics}

Top speed is considered the main parameter of dynamic performance for BELVs [47]. The top speed distribution of the various BELVs is shown in Figure 9. The present average top speed of BE minivan, the BE light truck and BE light bus is $95 \mathrm{~km} / \mathrm{h}, 89 \mathrm{~km} / \mathrm{h}$ and $100 \mathrm{~km} / \mathrm{h}$, respectively. The National Technical Committee for road transport standardization issued technical requirements for the selection of electric freight vehicles (Exposure Draft), in which the top speed in 30 min shall be increased to no less than $80 \mathrm{~km} / \mathrm{h}$ [62]. For vehicles with a total mass below $4500 \mathrm{~kg}$, the acceleration time from 0 to $50 \mathrm{~km} / \mathrm{h}$ shall be no more than $10 \mathrm{~s}$, while the acceleration time from 50 to $80 \mathrm{~km} / \mathrm{h}$ shall be no more than $15 \mathrm{~s}$. For vehicles with a total mass of at least $4500 \mathrm{~kg}$, the acceleration time from 0 to $50 \mathrm{~km} / \mathrm{h}$ shall be no more than $15 \mathrm{~s}$, and the acceleration time from 50 to $80 \mathrm{~km} / \mathrm{h}$ shall be no more than $20 \mathrm{~s}$. 


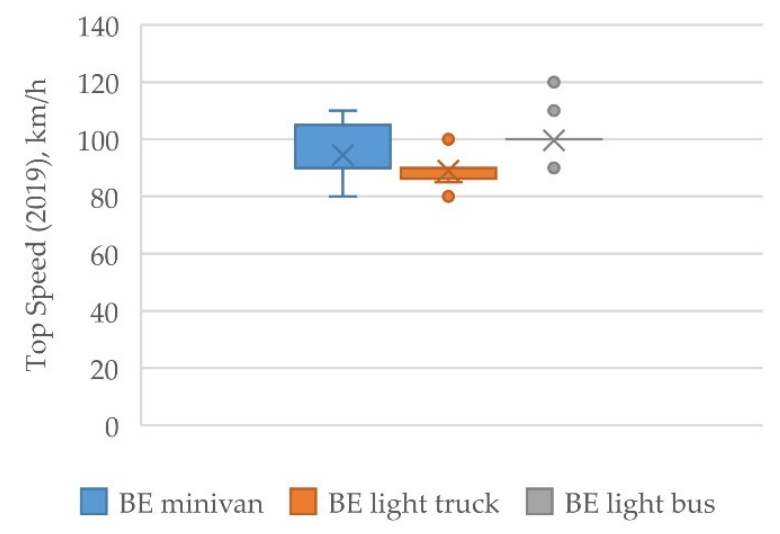

Figure 9. Top speed distribution of the various BELVs.

\subsection{Battery and Motor Technologies}

\subsubsection{Driving Power Distribution Characteristics}

Driving power is also considered the main parameter of dynamic performance for BELVs [47]. A plot of the driving power is shown in Figure 10. In 2017, the BE minivan had an average driving power of approximately $45 \mathrm{~kW}$, while the BE light truck and BE light bus are both rated at $55 \mathrm{~kW}$. In 2019, the BE minivan, the BE light truck and BE light bus had an average driving power of approximately $32 \mathrm{~kW}, 58 \mathrm{~kW}$ and $48 \mathrm{~kW}$, respectively.

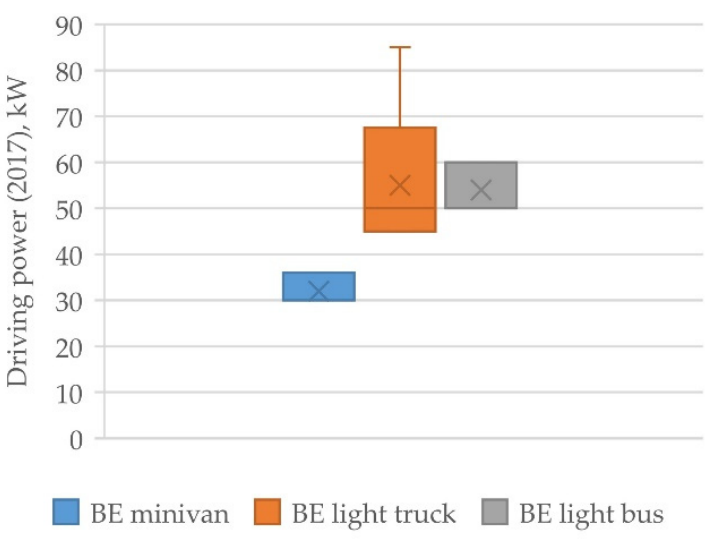

(a)

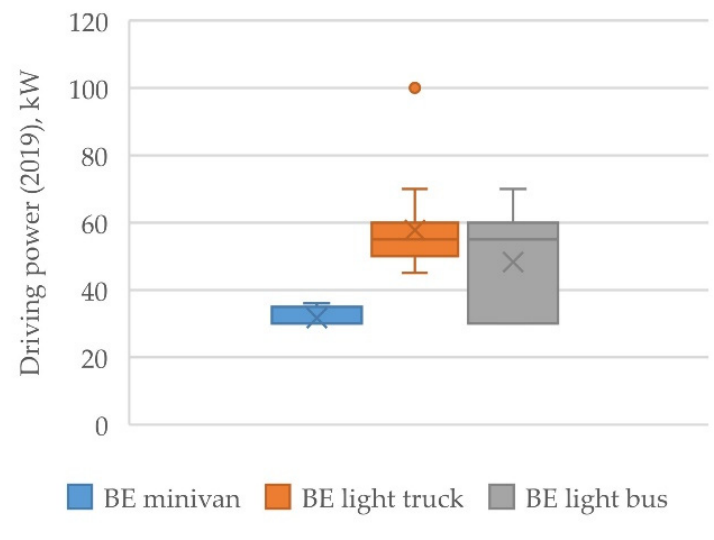

(b)

Figure 10. Driving power distribution of the various BELVs, (a) 2017 and (b) 2019.

\subsubsection{Energy Efficiency Distribution Characteristics}

With regard to the vehicle performance of BELVs, the energy consumption rate is an important parameter [8]. This parameter is expressed as $E_{k g}$ in the following Equation (1):

$$
E_{k g}=\frac{E}{M}
$$

where $E_{\mathrm{kg}}$ is the energy consumption per unit of mass, $\mathrm{Wh} /(\mathrm{km} \cdot \mathrm{kg}), M$ is the additional mass transported, $\mathrm{kg}$, and $E$ is the electricity consumption rate, $\mathrm{Wh} / \mathrm{km}$. Both values are measured according to the Chinese national standard (GB/T) 18386-2017.

According to GB/T 36980-2018, the energy consumption rate of an N1 BEV with a maximum design total mass not exceeding $3500 \mathrm{~kg}$ is limited. However, there is no energy consumption limit for BEVs with a maximum design total mass exceeding $3500 \mathrm{~kg}$. 
The National Technical Committee for road transport standardization issued technical requirements for the selection of electric freight vehicles (Exposure Draft), in which the energy consumption per unit of mass is required to not be higher than $0.45 \mathrm{Wh} /(\mathrm{km} \cdot \mathrm{kg})$ [62].

$E_{\mathrm{kg}}$ is a compound evaluation indicator used to determine the subsidy amount. The $E_{\mathrm{kg}}$ value of BELVs needs to be reduced. There is national technical standard to limit the $E_{k g}$ value of BELVs, and the national subsidy policy reflects the limit. The subsidy of BELVs is based on the battery's capacity, which provides the driving power, and the subsidy is issued by sectional excess accumulation. In the notice of 2018 [58], it is stipulated that if the $E_{\mathrm{kg}}$ value is higher than $0.4 \mathrm{Wh} /(\mathrm{km} \cdot \mathrm{kg})$, no subsidies will be granted, if the $E_{\mathrm{kg}}$ value ranges from 0.35 to $0.4 \mathrm{Wh} /(\mathrm{km} \cdot \mathrm{kg})$, a subsidy of 0.2 times will be issued, and if the $E_{\mathrm{kg}}$ value is $0.35 \mathrm{Wh} /(\mathrm{km} \mathrm{kg})$ or lower, the full subsidy amount will be granted. In the new policy of 2020 [57], it is stipulated that if the $E_{\mathrm{kg}}$ value is higher than $0.29 \mathrm{Wh} /(\mathrm{km} \cdot \mathrm{kg})$, it will not be subsidized.

Reducing the value of $E_{\mathrm{kg}}$ is the trend, and it is more challenging. In the future, improvements in lightweight technologies, thermal pump air conditioning and regenerative braking have a high potential for decreasing BELV energy consumption [47].

\subsubsection{Traction Battery Technology}

Lithium iron phosphate (LFP), nickel cobalt manganese (NCM) and lithium manganese oxide (LMO) batteries are the primary energy storage systems (ESSs). The market shares of the various ESSs are shown in Figure 11. LFP batteries have a better safety performance and charging cycle performance than NCM batteries [48]. In 2016, LFP batteries accounted for $84 \%$ of the market share. The ESS of NCM batteries gradually occupy the BELV market due to its higher energy-density performance, higher power density and better low-temperature performance, with its market share increasing from $6 \%$ to $39 \%$ over 4 years [13]. The energy density of the NCM battery has been increasing year by year, and from 2015 to 2018, it was 160, 180, 210 and $230 \mathrm{Wh} / \mathrm{kg}$, respectively [13]. With the gradual improvement of NCM technology, strict technical regulations and lightweight trends of logistics vehicles, NCM batteries will dominate the market in the medium terms [13].

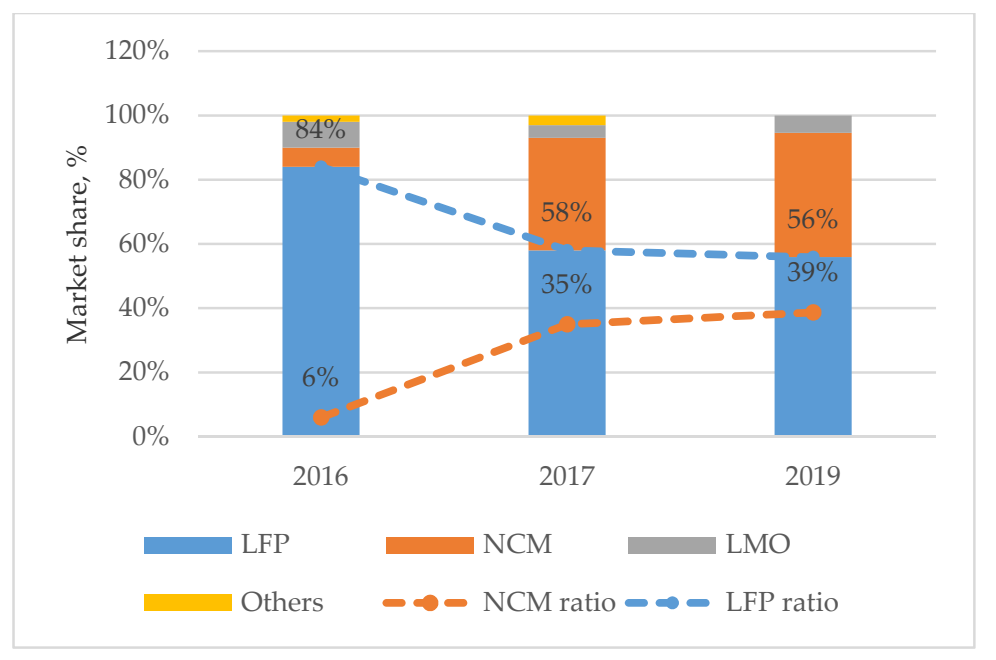

Figure 11. Market share of the various energy storage systems (ESSs) for BELVs.

As shown in Figure 12, the minimum battery capacity of BE minivan, BE light truck and BE light bus was approximately $40 \mathrm{kWh}, 70 \mathrm{kWh}$ and $68 \mathrm{kWh}$, respectively. 


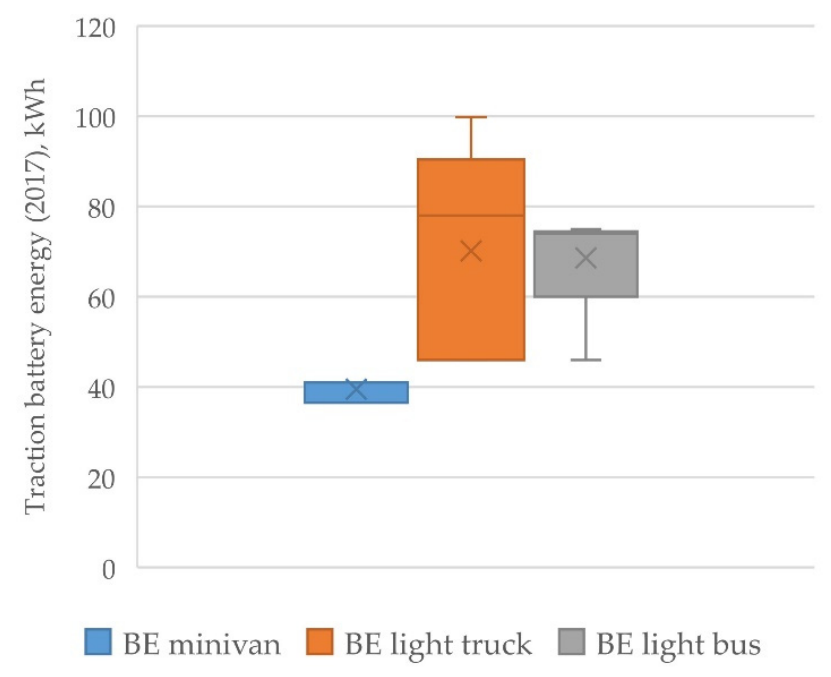

Figure 12. Battery capacity distribution for BELVs (2017).

On the one hand, the energy density of the battery is constantly increasing to reduce the battery self-weight. On the other hand, due to the battery production technology and scale effect, the battery cost is also decreasing. The battery price decreased to $1300 \mathrm{RMB} / \mathrm{kWh}$ in 2018 , down more than $50 \%$ compared with that in 2015 [63]. At the same time, the national subsidy standard is determined by the battery's capacity, and state subsidies are also decreasing year by year, as indicated in Table 1 .

\subsubsection{Traction Motor Technology}

In Chinese market, there are four types of BELV traction motors: (1) permanent magnet synchronous motors, (2) direct current (DC) brushless motors, (3) alternating current (AC) induction motors, and (4) permanent magnet reluctance motors. With the rapid development of motor controller technology in China, it has gradually reached the level of that of foreign-funded companies. Table 2 lists the technical index changes of the motor controller from 2010 to 2018 [13,64].

Table 2. The technical index changes of the traction motor controller from 2010 to 2018.

\begin{tabular}{ccccc}
\hline Index & PRIUS-2010 & CAMRY-2013 & BOSCH-2015 & Domestic Prototype-2018 \\
\hline Power Density (kW/L) & 11.1 & 19 & 12.8 & 25 \\
Power-to-Weight Ratio (kW/kg) & 16.7 & 17.2 & 10.5 & 16 \\
Power Semiconductor Device Type & IGBT & IGBT & IGBT & IGBT \\
DC Voltage Range (V) & $200-600$ & $200-600$ & $300-480$ & $300-480$ \\
Maximum Current (A) & 500 & 550 & 660 & 800 \\
\hline
\end{tabular}

IGBT means Insulated Gate Bipolar Transistor.

All 2019 BELVs models use the permanent magnet synchronous motors. Based on the changes of the technical indicators of the traction motor controller, the traction motor controller is developing towards the direction of high integration, high power density, high reliability and high safety.

\section{Challenges and Suggestions}

\subsection{Vehicle Performance and Reliability Issues Associated with BELVs}

The vehicle performance and reliability of currently used BELVs in the field of urban distribution are disadvantageous. Technical deficiencies lead to numerous problems, such as safety issues caused by misleading vehicle technical indicators, and the utilization rate of these vehicles is lower than that of fuel vehicles. The details are as follows.

(1) Vehicle performance comparison between BELVs and ICETs 
As presented in Section 4, compared with the same types of ICETs, the vehicle performance and reliability of currently used BELVs in the field of urban distribution are not beneficial, in terms of the CM, AER and energy efficiency. But all three parameters are improving year by year, constantly meeting logistics demands.

The payload of BELVs is significantly smaller than that of ICETs. For example, the CM of an NE light truck is $1500 \mathrm{~kg}$, only half of that of an ICE light truck.

Seen from the data of 2017 and 2019, all BELVs have increased in AER in recent years. At present, the range anxiety of BELV customers is not prominent. The relevant national standards have imposed requirements on the energy consumption per unit of mass $\left(E_{k g}\right)$, and the relevant national subsidy policies also include corresponding subsidy standards according to the $E_{\mathrm{kg}}$ value. Reducing the $E_{\mathrm{kg}}$ value is the trend, which has proven to be more challenging. In the future, improvements in lightweight technologies, thermal pump air conditioning and regenerative braking have a high potential for decreasing BELV energy consumption [36].

(2) Loss of trust in vehicle technical indicators leading to safety issues

The actual data of the CM, AER and $E_{k g}$ of BELVs produced by some automakers are not trustworthy. For example, there is a large gap between the actual and official AER data of some BELV models, which makes it impossible for BELV users to use this parameter to evaluate vehicle performance. In addition, some vehicle brands omit spare wheels to achieve the CM and load utilization factor. To meet the $E_{\mathrm{kg}}$ requirements, some manufacturers simplify the protection and temperature control devices of the battery [7], causing the hidden danger of spontaneous combustion. According to relevant reports, there have been dozens of spontaneous combustion accidents of NELVs in China since 2018 [65]. Figure 13 shows the fire causes of NELVs in China.

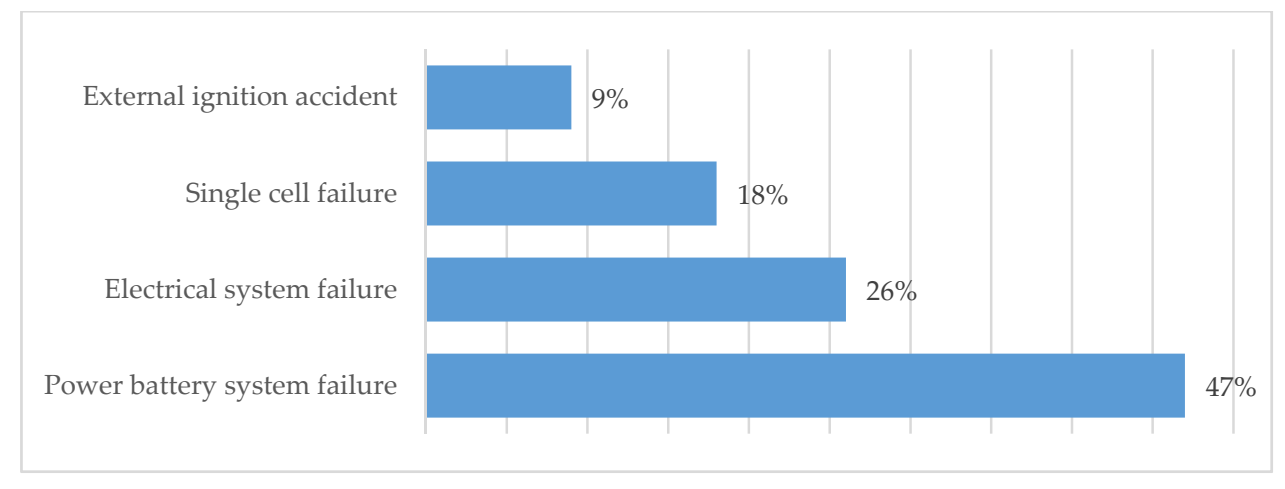

Figure 13. Distribution of the fire causes of NELVs in China.

(3) Vehicle utilization issues

BELV utilization is lower than that of ICETs. Due to the limitations of the current battery technology of BELVs, the one-charge AER does not satisfy the operation requirements for the whole day, so it is generally required to charge in the operation process. The inconveniences of a long single-charge time and a long queuing time seriously affect the operation efficiency. The slow charging time of most BELVs is generally $8-12 \mathrm{~h}$, and the fast-charging time is $2 \mathrm{~h}$. BELVs are generally fully charged overnight. However, due to the AER limit, many users have to recharge batteries at least once in the daytime. Generally, the charging time is approximately half an hour, and including the waiting time, charging usually requires more than one hour. To reduce the fuel cost, add-on and plug-in vehicles generally need to be refueled twice a day, while ICETs usually need to be refueled only once every $4-5$ days.

On the other hand, at present, the AER of BELVs under low-temperature conditions will generally decrease by approximately $20 \%$, and the charging time will increase by about $50 \%$ [7]. This leads to a decrease in vehicle utilization in winter compared with that in summer. With the increase in vehicle age and decrease in the battery's capacity, the vehicle utilization rate further decreases. 


\subsection{Total Costs and Benefits of Subsidies for BELVs}

The logistics industry is a highly cost-sensitive heavy-asset industry, and transportation vehicles are one of the most important means of production in the logistics industry. Therefore, the vehicle total cost of operation (TCO) is one of the key factors for logistics service providers to decide whether to use NELVs. With the decline of subsidies, the cost of NELVs will continue to rise. How to reduce the TCO will be the main problem facing engine plants, operation companies and users.

(1) Total cost comparison between BELVs and ICETs

Compared with ICETs, BELVs are not superior to ICETs in terms of vehicle performance and reliability or in terms of the TCO [13]. At present, mainstream insurance companies have insured BEVs according to the price before the subsidy, and the premium for BEVs of the same model is higher than that of fuel vehicles. Subsidies decrease while battery production costs decrease as well. The tipping point for BEVs to become cheaper to produce than petrol equivalents is expected to be reached by 2024, whereas three years ago, this was expected by 2026, indicating how quickly these things tend to evolve [18]. The TCO is still a great challenge in promoting BELVs over the next 5 years.

(2) Evaluation of the benefit of subsidies for the different BELV models

Relevant studies have analyzed the influence of subsidies on the development of BEBs in China, and the conclusion is as follows: the subsidy efficiency for the different sizes of BEBs is not reasonable owing to the poor performance of heavy-duty BEBs. However, the total fossil energy replacement for light-duty BEBs is comparably higher due to the higher available subsidy [47,48]. Therefore, is the subsidy of NELVs reasonable? Is the subsidy policy inclined to a certain model? The following is an analysis of the impact of subsidy policies on the various BELV models.

- Subsidy offset rate

The price (or cost) difference between a BELV and an ICET as well as the subsidy offset rate (SOR) can be considered as evaluation indicators. The SOR can be calculated using the following Equation (2):

$$
\text { subsidy of } f \text { set rate }=\frac{S_{B E L V}}{M R S P_{B E L V}-M R S P_{I C E T}} \times 100 \%
$$

where $S_{B E L V}$ is the total national and local government subsidy amount, and $M R S P_{B E L V}$ and $M R S P_{I C E T}$ are the manufacture retail prices (MRSPs) of typical BELVs and ICETs, respectively.

The MRSPs of typical BELVs and ICETs, the subsidy offset rate and the difference between the ICET price and the post-subsidy price of BELVs were analyzed, as shown in Figure 14.

As shown in Figure 14, the MRSP of typical BELVs in 2017 is 2-3 times that of ICETs. Subsidies decrease while battery production costs decrease as well. The subsidies for BELVs are decreasing year by year, and the difference between the ICET price and the post-subsidy price of BELVs is increasing year by year. The subsidy offset rate values in 2017 were approximately $110 \%$, and the post-subsidy price differences were negative. The post-subsidy prices of all typical BELVs are lower than those of ICETs. Taking the BE minivan as an example, a fiscal subsidy amount of 80,000 RMB can be obtained from the central government and provinces. The post-subsidy price of the BE minivan is only $30,000 \mathrm{RMB}$, but the MRSP of an ICE minivan is 40,000 RMB. Because the MRSP of the BE minivan is much lower than that of the BE light bus and light truck, many operators and logistics companies have bought a large number of BE minivans. In 2018 and 2019, the subsidy offset rates were approximately $70 \%$ and $20 \%$ respectively, and all subsidies may be cancelled by the end of 2020 . It can also be seen that there is no significant difference in the subsidy offset rates of BE minivans, light trucks and light buses, and the subsidy offset rate for a BE light truck is slightly lower, which implies that subsidy policies do not favor a certain vehicle model. 


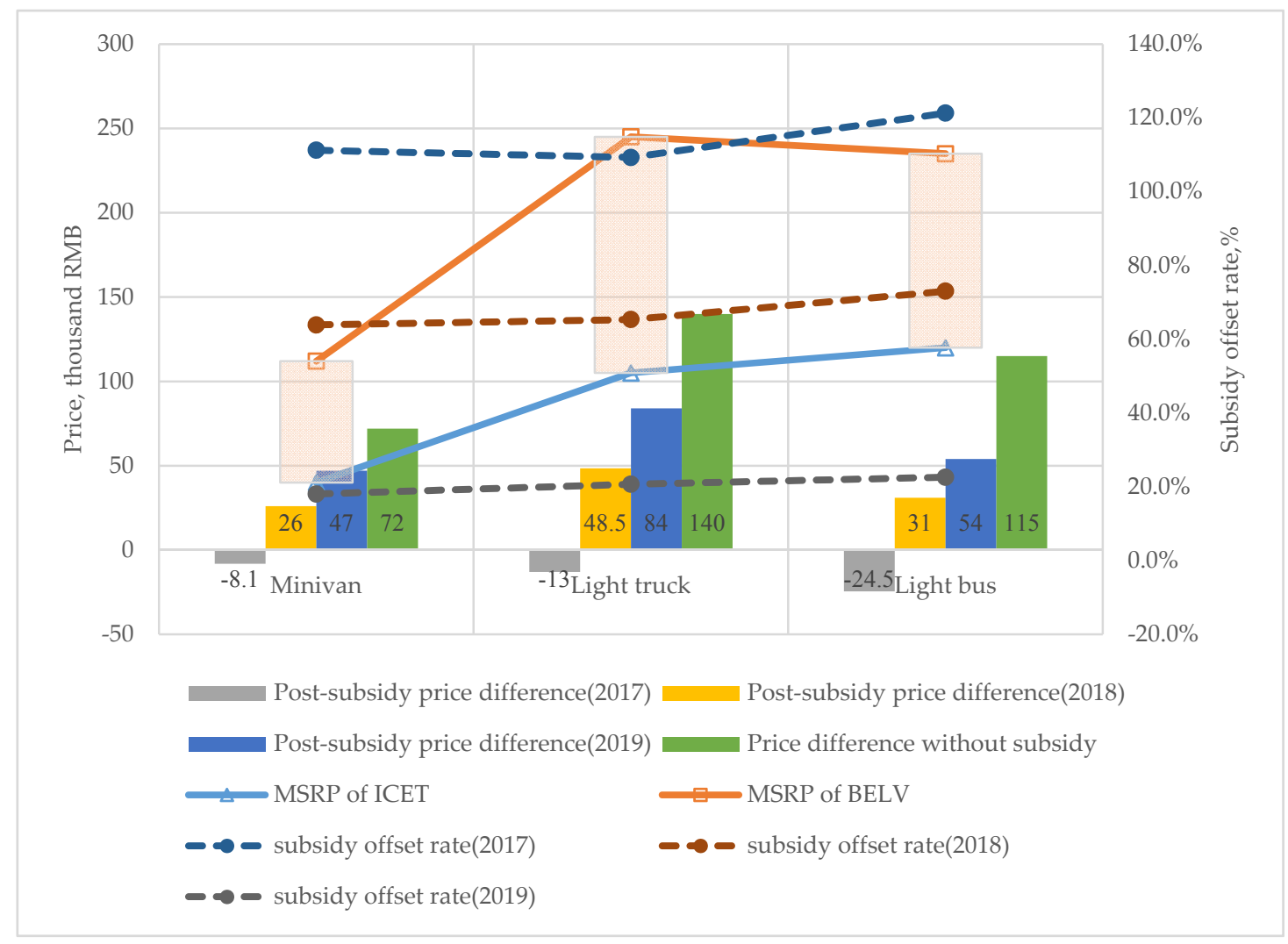

Figure 14. The price difference for the various BELVs.

Although the price of the battery system is declining rapidly and the price of BELVs is also declining rapidly, in the absence of subsidies, the price of BELVs is still 2-3 times that of ICETs. This is a great challenge in promoting BELVs. Therefore, it is indicated that subsidy schemes should be prolonged after 2020 to make sure the EV-market becomes self-sustainable.

- Subsidy efficiency

Furthermore, the evaluation indicator of the subsidy efficiency $\left(S_{\text {eff }}\right)$ is proposed here to clarify the effect of subsidies on fuel displacement. It is defined as the subsidy of fuel replacement. $S_{\text {eff }}$ can be calculated by the following Equations (3)-(5):

$$
\begin{gathered}
S_{e f f}=\frac{S_{B E L V}}{C_{I C E T}} \\
C_{I C E T}=\frac{F_{e} \times R \times d \times c_{f}}{100} \\
C_{B E L V}=\frac{E_{e} \times R \times d \times c_{e}}{100}
\end{gathered}
$$

where $S_{B E L V}$ is the total national and local government subsidy amount, $C_{I C E T}$ and $C_{B E L V}$ are the annual energy consumption costs of an ICET and a BELV respectively, $F_{e}$ is the fuel consumption of an ICET travelling $100 \mathrm{~km}, \mathrm{~L} / 100 \mathrm{~km}, E_{e}$ is the battery consumption of a BELV travelling $100 \mathrm{~km}, \mathrm{kWh} / 100$ $\mathrm{km}, R$ is the daily millage, $\mathrm{km}, d$ represents the annual operation days $(d=300), c_{f}$ is the unit price of fuel $\left(c_{f}=6.8 \mathrm{RMB} / \mathrm{L}\right)$ and $c_{e}$ is the unit price of electricity $\left(c_{e}=1 \mathrm{RMB} / \mathrm{kWh}\right)$.

Figure 15 shows the energy consumption comparison between BELVs and ICETs. The figure reveals that the energy consumed by an ICET is approximately twice that of a BELV. In addition, there is little difference in the subsidy efficiency among the different models of logistic vehicles, and the 
subsidy efficiency for light trucks is slightly lower. This result is consistent with the subsidy offset, which again shows that subsidy policies do not favor a certain logistic vehicle model.

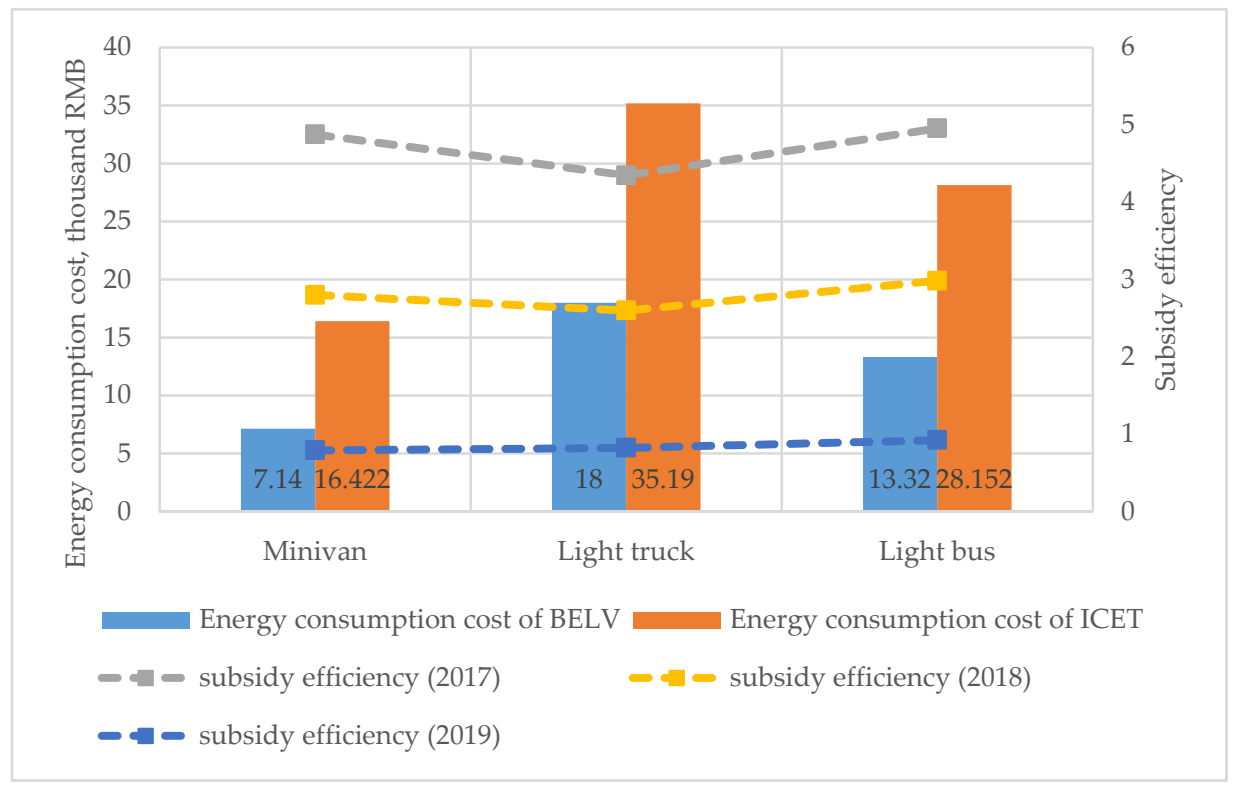

Figure 15. Energy consumption comparison between BELVs and internal combustion engine trucks (ICETs).

The national subsidy threshold for BELVs is increasing year by year. The above analysis also shows that the subsidy conditions are gradually becoming reasonable. The BELV industry is gradually leaving the era of subsidies and developing towards mass-adaption by consumers.

\subsection{Suggestions}

According to the key challenges analyzed in Sections 5.1 and 5.2, it is necessary to improve the level of vehicle parameters such as the CM, AER, energy efficiency and charging efficiency, and develop the technology of power exchange and charging. To improve the vehicle performance and use efficiency, suggestions for the technical development direction of BELVs are as follows.

(1) To reduce the CM and increase the AER for BELVs, high-energy, high-quality and low-cost battery technologies should be widely applied.

(2) Reducing the $E_{k g}$ value is the trend, and it is more challenging. In the future, improvements in lightweight technologies, thermal pump air conditioning and regenerative braking have a high potential for decreasing BELV energy consumption [47].

(3) With the gradual improvement of NCM technology, strict technical regulations and lightweight trends of logistics vehicles, NCM batteries will dominant the market in the medium terms.

(4) With the rapid development of motor controller technology in China, it has gradually reached the level of that of foreign-funded companies. The changes in the technical indicators of the traction motor controller indicate that the traction motor controller is developing towards the direction of high integration, high-power density, high reliability and high safety.

(5) In response to battery decay, it is recommended that the government incentivize manufacturers to make better batteries and strengthen the management of battery recycling and reprocessing.

(6) In addition, Internet of Things (IoT) with inter-connected vehicles should be fully applied to BELVs to give full play to the role of BELVs in Intelligent Logistics. Through analysis of BELV positioning data, we can optimize the construction layout of charging supporting facilities, improve the utilization rate of vehicles and charging piles, and promote cost reduction, efficiency improvement and virtuous cycle development in the NE and logistics industries. 
(7) In response to the safety problems caused by the loss of trust in vehicle technical indicators, it is recommended to establish strict technical standards and promote a unified NELVs monitoring service platform. China has mainly solved them by setting technical standards and establishing a strict safety regulatory system. This paper suggests that the whole life-cycle management of vehicles can be carried out by developing a standardization system to guarantee the quality of vehicle manufacturing and regulate the operation and use process of vehicles [7].

In 2016, Ministry of Industry and Information Technology of the People's Republic of China (MIIT) proposed the requirement of safety supervision of NEVs [66]. The monitoring and management platform of the NEVs focuses only on the operational status of NEVs at present [7]. It is recommended to establish and promote a unified NELVs monitoring service platform, access to operational vehicle information and supervision, in order to guarantee the safety of the entire industry chain and life-cycle of NEVs.

\section{Conclusions}

This study aimed to comprehensively study the development of BELVs in China and was primarily based on technical and industrial data of all BELVs available in the Chinese market. Several insights into the ongoing evolution of BELVs in recent years were obtained through a comprehensive analysis.

Firstly, despite the declining subsidies for NEVs and sluggish growth of the new energy bus (NEB) industry, the NELV industry has bucked the trend, and its output has risen sharply. The main market penetration's influencing factors include favorable policies, improvement of the NEV technology level, public awareness of environmental protection and market awareness.

Secondly, an evaluation system comprising 8 technological indicators for evaluating BELV performance and technological progress was proposed. The characteristics of the curb mass, vehicle volume, all-electric range, top speed, driving power, energy efficiency, traction battery and motor technology were analyzed for the 2017 and 2019 market's models. Compared with the same types of ICETs, the vehicle performance and reliability of currently used BELVs in the field of urban distribution are not beneficial, in terms of the CM, AER and energy efficiency. The shortcomings in the performance of BELVs also result in various problems, such as safety issues caused by misleading vehicle technical indicators, and the utilization rate of vehicles is lower than that of fuel vehicles. But all the parameters are improving year by year, constantly meeting logistics demands in recent years. In 2019, the average AER for BE minivans, BE light trucks and BE light buses were approximately $255 \mathrm{~km}, 241 \mathrm{~km}$ and $233 \mathrm{~km}$, respectively. The average $\mathrm{CM}$ of BE minivans, BE light trucks and BE light buses were approximately $935 \mathrm{~kg}, 1381 \mathrm{~kg}$ and $1308 \mathrm{~kg}$, respectively.

Thirdly, the benefit of subsidies for the different BELV models has been evaluated. Because the MRSP of BE minivans is much lower than that of BE light buses and light trucks, many operators and logistics companies have bought a large number of BE minivans. It was revealed that the subsidy policy does favor a certain vehicle model, and the subsidy conditions for BELVs are gradually becoming reasonable. The TCO is still a great challenge in promoting BELVs over the next 5 years. The subsidies are needed for longer for the market to mature. The BELV industry is gradually leaving the era of subsidies and developing towards mass-adaption by consumers.

Finally, several suggestions for the technical development direction of BELVs were proposed. It is necessary to improve the level of vehicle parameters such as the CM, AER, energy efficiency and charging efficiency and develop the technology of power exchange and charging. In response to battery decay, it was recommended that the government incentivizes manufacturers to make better batteries and strengthen the management of battery recycling and reprocessing. In response to the safety problems caused by the loss of trust in vehicle technical indicators, it was recommended to establish strict technical standards and promote a unified NELVs monitoring service platform.

In general, this research contributed to providing a better understanding of the technology development characteristics of BELVs by using marketing and technological data in China. In addition, market penetration's influencing factors for BELVs were analyzed, and the benefit of subsidies for 
different BELV models was evaluated. All these results can be used to improve the vehicle performance, reliability and market penetration of BELVs and propose new incentive policies for BELVs. However, there are still unsolved problems in the analysis of their technological characteristics. In the process of analyzing the energy efficiency, because there are no complete data on the electricity consumption rate of the various models on the market, it is impossible to calculate the $E_{k g}$ value. The development requirements of $E_{\mathrm{kg}}$ have only been revealed by comparing relevant national standards and national financial subsidies, which should be further studied in the future.

Author Contributions: X.J. contributed to this research article in the conceptualization, methodology, formal analysis, investigation, resources, data curation and writing. X.G. contributed to this research article for methodology and funding acquisition. All authors have read and agreed to the published version of the manuscript.

Funding: This research was funded by the Social Science Research Foundation of Jiangsu Province (grant no.18WTA009), and Research subject of China logistics association (grant no.2019CSLKT3-032).

Acknowledgments: We gratefully acknowledge the experts who participated in the study and thank Wei Yu for his valuable comments on early drafts.

Conflicts of Interest: The authors declare no conflict of interest.

\section{Abbreviations}

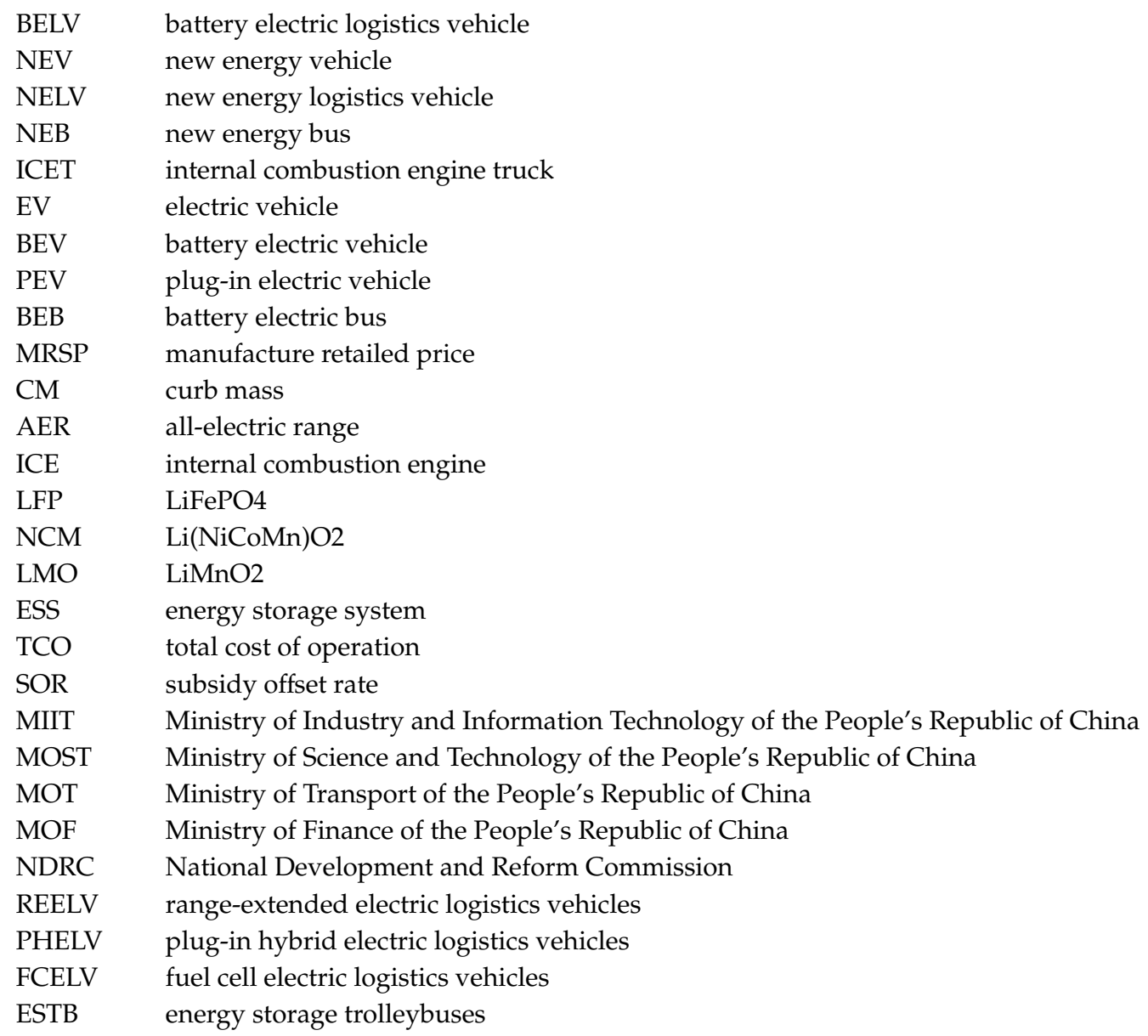

\section{References}

1. State Post Bureau of China. Global Express Development Report; Development Research Center of State Post Office: Beijing, China, 2019.

2. Ministry of Environmental Protection of Republic of China. Annual Report of Chinese Vehicles Pollution Control Ministry of Environmental Protection of Republic of China; Ministry of Environmental Protection of Republic of China: Beijing, China, 2018. 
3. Ministry of Public Security of China. The Number of Private Cars in China Exceeded 200 Million for the First Time. Available online: https://www.mps.gov.cn/n2254314/n6409334/c6852472/content.html (accessed on 10 February 2020).

4. China State Council. Circular of the State Council on the Issuance of an Action Plan to Combat Air Pollution. Available online: http://www.gov.cn/zwgk/2013-09/12/content_2486773.htm (accessed on 10 August 2019).

5. Duarte, G.; Rolim, C.; Baptista, P. How battery electric vehicles can contribute to sustainable urban logistics: A real-world application in Lisbon, Portugal. Sustain. Energy Technol. Assess. 2016, 15, 71-78. [CrossRef]

6. Fiori, C.; Marzano, V. Modelling energy consumption of electric freight vehicles in urban pickup/delivery operations: Analysis and estimation on a real-world dataset. Transp. Res. Part D Transp. Environ. 2018, 65, 658-673. [CrossRef]

7. Highway Research Institute of the Ministry of Transport; Panda Zhi Lian. Application Analysis Report of New Energy Logistics Vehicle for Urban Green Freight Transportation; Highway Research Institute of the Ministry of Transport: Beijing, China, 2019.

8. Mahmoudzadeh Andwari, A.; Pesiridis, A.; Rajoo, S.; Martinez-Botas, R.; Esfahanian, V. A review of Battery Electric Vehicle technology and readiness levels. Renew. Sustain. Energy Rev. 2017, 78, 414-430. [CrossRef]

9. Shen, Z.M.; Feng, B.; Mao, C.; Ran, L. Optimization models for electric vehicle service operations: A literature review. Transp. Res. Part B Methodol. 2019, 128, 462-477. [CrossRef]

10. Teoh, T.; Kunze, O.; Teo, C.; Wong, Y. Decarbonisation of Urban Freight Transport Using Electric Vehicles and Opportunity Charging. Sustain. Basel 2018, 10, 3258. [CrossRef]

11. Srithapon, C.; Ghosh, P.; Siritaratiwat, A.; Chatthaworn, R. Optimization of Electric Vehicle Charging Scheduling in Urban Village Networks Considering Energy Arbitrage and Distribution Cost. Energies 2020, 13, 349. [CrossRef]

12. Yang, J.; Dong, J.; Hu, L. Design government incentive schemes for promoting electric taxis in China. Energy Policy 2018, 115, 1-11. [CrossRef]

13. Chinese New Energy Logistics Vehicle Development Report Compilation Committee; National Engineering Laboratory of Logistics Information Interconnection and Sharing Technology and Application; Shanghai Qianming Enterprise Management Consulting Company. Development Report of 2018 Chinese New Energy Logistics Vehicles; Fudan University Press: Shanghai, China, 2019.

14. Weiss, M.; Patel, M.K.; Junginger, M.; Perujo, A.; Bonnel, P.; van Grootveld, G. On the electrification of road transport - Learning rates and price forecasts for hybrid-electric and battery-electric vehicles. Energy Policy 2012, 48, 374-393. [CrossRef]

15. Cheng, G.; Liu, C. Research on Business Operating Model of New Energy Battery Electric Vehicles Used as Urban Logistics Cars. Int. J. Multimed. Ubiquitous Eng. 2016, 11, 387-400. [CrossRef]

16. Zhang, H.; Song, X.; Xia, T.; Yuan, M.; Fan, Z.; Shibasaki, R.; Liang, Y. Battery electric vehicles in Japan: Human mobile behavior based adoption potential analysis and policy target response. Appl. Energy 2018, 220, 527-535. [CrossRef]

17. Yong, T.; Park, C. A qualitative comparative analysis on factors affecting the deployment of electric vehicles. Energy Procedia 2017, 128, 497-503. [CrossRef]

18. Hardman, S.; Chandan, A.; Tal, G.; Turrentine, T. The effectiveness of financial purchase incentives for battery electric vehicles-A review of the evidence. Renew. Sustain. Energy Rev. 2017, 80, 1100-1111. [CrossRef]

19. Sun, L.; Huang, Y.; Liu, S.; Chen, Y.; Yao, L.; Kashyap, A. A completive survey study on the feasibility and adaptation of EVs in Beijing, China. Appl. Energy 2017, 187, 128-139. [CrossRef]

20. Massiani, J. Cost-Benefit Analysis of policies for the development of electric vehicles in Germany: Methods and results. Transp. Policy 2015, 38, 19-26. [CrossRef]

21. Wolinetz, M.; Axsen, J. How policy can build the plug-in electric vehicle market: Insights from the REspondent-based Preference And Constraints (REPAC) model. Technol. Forecast Soc. 2017, 117, 238-250. [CrossRef]

22. Wang, S.; Li, J.; Zhao, D. The impact of policy measures on consumer intention to adopt electric vehicles: Evidence from China. Transp. Res. Part A Policy Pract. 2017, 105, 14-26. [CrossRef]

23. Zhang, X.; Liang, Y.; Yu, E.; Rao, R.; Xie, J. Review of electric vehicle policies in China: Content summary and effect analysis. Renew. Sustain. Energy Rev. 2017, 70, 698-714. [CrossRef]

24. Da Silva, R.E.; Sobrinho, P.M.; de Souza, T.M. How can energy prices and subsidies accelerate the integration of electric vehicles in Brazil? An economic analysis. Electr. J. 2018, 31, 16-22. [CrossRef] 
25. Zhang, L.; Qin, Q. China's new energy vehicle policies: Evolution, comparison and recommendation. Transp. Res. Part A Policy Pract. 2018, 110, 57-72. [CrossRef]

26. Greene, D.L.; Park, S.; Liu, C. Public policy and the transition to electric drive vehicles in the U.S.: The role of the zero emission vehicles mandates. Energy Strategy Rev. 2014, 5, 66-77. [CrossRef]

27. Longjian, P.; Qian, A.; Zhiwen, Y.; Jingpeng, C. Multi-agent-based Pricing Strategy for Electric Vehicle Charging Considering Customer Satisfaction Degree. Autom. Electric. Power Syst. 2015, 39, 68-82.

28. Faccio, M.; Gamberi, M. New City Logistics Paradigm: From the "Last Mile" to the "Last 50 Miles" Sustainable Distribution. Sustain. Basel 2015, 7, 14873-14894. [CrossRef]

29. Muñoz-Villamizar, A.; Montoya-Torres, J.R.; Faulin, J. Impact of the use of electric vehicles in collaborative urban transport networks: A case study. Transp. Res. Part D Transp. Environ. 2017, 50, 40-54. [CrossRef]

30. Mareev, I.; Becker, J.; Sauer, D. Battery Dimensioning and Life Cycle Costs Analysis for a Heavy-Duty Truck Considering the Requirements of Long-Haul Transportation. Energies 2018, 11, 55. [CrossRef]

31. Sim, K.; Vijayagopal, R.; Kim, N.; Rousseau, A. Optimization of Component Sizing for a Fuel Cell-Powered Truck to Minimize Ownership Cost. Energies 2019, 12, 1125. [CrossRef]

32. Lee, D.; Thomas, V.M.; Brown, M.A. Electric Urban Delivery Trucks: Energy Use, Greenhouse Gas Emissions, and Cost-Effectiveness. Environ. Sci. Technol. 2013, 47, 8022-8030. [CrossRef]

33. Figliozzi, M.; Saenz, J.; Faulin, J. Minimization of urban freight distribution lifecycle CO2e emissions: Results from an optimization model and a real-world case study. Transp. Policy 2018, 86, 60-68. [CrossRef]

34. De Mello Bandeira, R.A.; Goes, G.V.; Schmitz Gonçalves, D.N.; D’Agosto, M.D.A.; Oliveira, C.M.D. Electric vehicles in the last mile of urban freight transportation: A sustainability assessment of postal deliveries in Rio de Janeiro-Brazil. Transp. Res. Part D Transp. Environ. 2019, 67, 491-502. [CrossRef]

35. Juan, A.; Mendez, C.; Faulin, J.; de Armas, J.; Grasman, S. Electric Vehicles in Logistics and Transportation: A Survey on Emerging Environmental, Strategic, and Operational Challenges. Energies 2016, 9, 86. [CrossRef]

36. Taefi, T.T.; Kreutzfeldt, J.; Held, T.; Fink, A. Supporting the adoption of electric vehicles in urban road freight transport-A multi-criteria analysis of policy measures in Germany. Transp. Res. Part A Policy Pract. 2016, 91, 61-79. [CrossRef]

37. Tipagornwong, C.; Figliozzi, M. Analysis of Competitiveness of Freight Tricycle Delivery Services in Urban Areas. Transp. Res. Rec. J. Transp. Res. Board 2014, 2410, 76-84. [CrossRef]

38. Ahani, P.; Arantes, A.; Melo, S. A portfolio approach for optimal fleet replacement toward sustainable urban freight transportation. Transp. Res. Part D Transp. Environ. 2016, 48, 357-368. [CrossRef]

39. Anna Corinna Cagliano, A.C.G.M. Analyzing the diffusion of eco-friendly vans for urban freight distribution. Int. J. Logist. Manag. 2016, 28, 1218-1242. [CrossRef]

40. Lebeau, P.; Macharis, C.; Van Mierlo, J. Exploring the choice of battery electric vehicles in city logistics: A conjoint-based choice analysis. Transp. Res. Part E Logist. Transp. Rev. 2016, 91, 245-258. [CrossRef]

41. Wikström, M.; Hansson, L.; Alvfors, P. Investigating barriers for plug-in electric vehicle deployment in fleets. Transp. Res. Part D Transp. Environ. 2016, 49, 59-67. [CrossRef]

42. Yu, W.; Tao, W.; Yan, Z.; Jun, C. Parameter Selection and Evaluation of Robustness of Nanjing Metro Network Based on Supernetwork. IEEE Access 2019, 7, 70876-70890. [CrossRef]

43. Muñoz-Villamizar, A.; Quintero-Araújo, C.L.; Montoya-Torres, J.R.; Faulin, J. Short- and mid-term evaluation of the use of electric vehicles in urban freight transport collaborative networks: A case study. Int. J. Logist. Res. Appl. 2019, 22, 229-252. [CrossRef]

44. Zhang, Y.; Chen, J.; Li, X.; Zhong, M. Exploring logistics dispatcher's preference in electric tricycle related policies: The case of China. J. Clean. Prod. 2019, 230, 835-843. [CrossRef]

45. Sun, X.; Li, Z.; Wang, X.; Li, C. Technology Development of Electric Vehicles: A Review. Energies 2020, 13, 90. [CrossRef]

46. Du, J.; Ouyang, M.; Chen, J. Prospects for Chinese electric vehicle technologies in 2016-2020: Ambition and rationality. Energy 2017, 120, 584-596. [CrossRef]

47. Du, J.; Li, F.; Li, J.; Wu, X.; Song, Z.; Zou, Y.; Ouyang, M. Evaluating the technological evolution of battery electric buses: China as a case. Energy 2019, 176, 309-319. [CrossRef]

48. Du, J.; Ouyang, M.; Wu, X.; Meng, X.; Li, J.; Li, F.; Song, Z. Technological direction prediction for battery electric bus under influence of China's new subsidy scheme. J. Clean. Prod. 2019, 222, 267-279. [CrossRef]

49. Manzetti, S.; Mariasiu, F. Electric vehicle battery technologies: From present state to future systems. Renew. Sustain. Energy Rev. 2015, 51, 1004-1012. [CrossRef] 
50. MOF. MOST Notice on the Implementation of Energy-Saving and New Energy Vehicle Demonstration and Promotion Pilot Work. Available online: http://www.most.gov.cn/fggw/zfwj/zfwj2009/200902/t20090224_ 67588.htm. (accessed on 15 November 2019).

51. MOF. MOST Notice on the Continuation of the Pilot Work on the Demonstration and Promotion of Energy-Saving and New Energy Vehicles. Available online: http://www.most.gov.cn/tztg/201309/t20130917_ 109405.htm (accessed on 15 November 2019).

52. MIIT. Announcement on New Energy Vehicles Exempt from Vehicle Purchase Tax. Available online: http://www.miit.gov.cn/n11293472/n11293832/n12845605/n13916898/16091756.html (accessed on 15 November 2019).

53. MOF. Announcement on Travel Tax Relief On Energy Saving and New Energy Vehicles Exempt from Vehicle Travel Tax. Available online: http://szs.mof.gov.cn/zhengwuxinxi/zhengcefabu/201505/t20150515_1232375. html (accessed on 15 November 2019).

54. NDRC Notice of NDRC on the Electric Vehicle Policy Issues Related to Electricity Prices. Available online: http://jgs.ndrc.gov.cn/zcfg/201408/t20140801_621052.html (accessed on 15 November 2019).

55. The State Council of the Central Committee of the Communist Party of China issued the Outline of Building a Powerful Nation in Transportation. Available online: http://www.gov.cn/zhengce/2019-09/19/content_ 5431432.htm (accessed on 15 November 2019).

56. MOF; MOST; MIIT. NDRC Notice of Financial Support Policy for the Promotion and Application of New Energy Vehicles in 2016-2020. Available online: http://www.most.gov.cn/tztg/201505/t20150507_119246.htm (accessed on 15 November 2019).

57. MOF; MIIT; MOST. NDRC Notice of the Four Ministries on Improving the Promotion and Application of new Energy Vehicles Financial Subsidy Policy. Available online: http://www.miit.gov.cn/n1146290/n1146402/ c7883101/content.html (accessed on 25 April 2020).

58. MOF; MIIT; MOST. NDRC Notice of the Four Ministries on Adjusting and Perfecting the Financial Subsidy Policy for the Promotion and Application of New Energy Vehicles. Available online: http://www.miit.gov.cn/ n1146295/n1652858/n1652930/n3757018/c6064786/content.html (accessed on 15 November 2019).

59. National Automobile Standardization Technical Committee. Technical specifications of remote service and management system for electric vehicles-Part 3: Communication protocol and data format. In GB/T 32960.3-2016; Standardization Administration of China: Beijing, China, 2016.

60. Circular of the Traffic Police Bureau of Shenzhen Public Security Bureau on the Continued Implementation of the Regulations for Electronic Filing of New Energy Pure Electric Logistics Vehicles. Available online: http://search.sz.gov.cn/cn/xxgk/zfxxgj/tzgg/201902/t20190213_16392054.htm (accessed on 15 November 2019).

61. A Library of Battery Electric Logistics Vehicle Models for Chinese Market. Available online: http://www. evpartner.com/zyc/CarIndex (accessed on 5 February 2020).

62. National Technical Committee on Road Transport Standardization. Technical Requirements for the Selection of Electrically Operated Freight Vehicles (Exposure Draft); Standardization Administration of China: Beijing, China, 2017.

63. How to Break Through the Fierce Competition when the Power Battery Overcapacity Will Reach the Peak in 2018? Available online: http://www.evpartner.com/news/68/detail-34825.html (accessed on 5 October 2019).

64. Product Introduction of Shanghai EORIVE Co., LTD. Available online: http://www.chinaedrive.com/pro.aspx (accessed on 19 July 2019).

65. Yiliang, R.; Jia, W. Analysis and Countermeasures of New Energy Vehicle Fire Accident in China. Automot. Digest 2019, 5, 39-43.

66. MIIT Notice of the Ministry of Industry and Information Technology on Further Improving the Safety Supervision of the Promotion and Application of New Energy Vehicles. Available online: http://www.miit. gov.cn/n1146295/n1652858/n1652930/n3757018/c5362809/content.html (accessed on 15 November 2019).

(C) 2020 by the authors. Licensee MDPI, Basel, Switzerland. This article is an open access article distributed under the terms and conditions of the Creative Commons Attribution (CC BY) license (http://creativecommons.org/licenses/by/4.0/). 